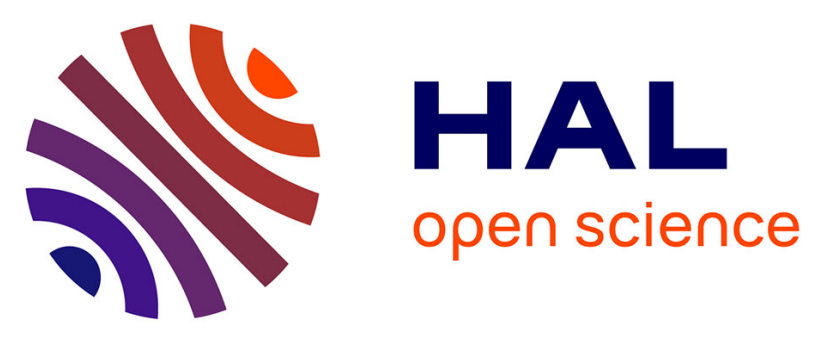

\title{
Lactic acidosis together with GM-CSF and M-CSF induces human macrophages toward an inflammatory pro-tumor phenotype
}

Léa Paolini, Clément Adam, Céline Beauvillain, Laurence Preisser, Simon Blanchard, Pascale Pignon, Valérie Seegers, Louise-Marie Chevalier, Mario Campone, Romuald Wernert, et al.

\section{To cite this version:}

Léa Paolini, Clément Adam, Céline Beauvillain, Laurence Preisser, Simon Blanchard, et al.. Lactic acidosis together with GM-CSF and M-CSF induces human macrophages toward an inflammatory protumor phenotype. Cancer Immunology Research, 2020, 8 (3), pp.383-395. 10.1158/2326-6066.CIR18-0749 . hal-02442525

HAL Id: hal-02442525

https://hal-univ-rennes1.archives-ouvertes.fr/hal-02442525

Submitted on 17 Feb 2020

HAL is a multi-disciplinary open access archive for the deposit and dissemination of scientific research documents, whether they are published or not. The documents may come from teaching and research institutions in France or abroad, or from public or private research centers.
L'archive ouverte pluridisciplinaire HAL, est destinée au dépôt et à la diffusion de documents scientifiques de niveau recherche, publiés ou non, émanant des établissements d'enseignement et de recherche français ou étrangers, des laboratoires publics ou privés. 


\section{Lactic acidosis together with GM-CSF and M-CSF induces human macrophages toward an inflammatory pro-tumor phenotype}

Running title: Lactate induces inflammatory pro-tumor macrophages

Léa Paolini ${ }^{1, \#}$, Clément Adam ${ }^{1, \#}$, Céline Beauvillain ${ }^{1,2}$, Laurence Preisser ${ }^{1}$, Simon

Blanchard $^{1,2}$, Pascale Pignon ${ }^{1}$, Valérie Seegers ${ }^{1,3}$, Louise-Marie Chevalier ${ }^{1,3}$, Mario

Campone $^{1,3}$, Romuald Wernert ${ }^{3}$, Véronique Verrielle ${ }^{3}$, Pedro Raro $^{3}$, Norbert Ifrah ${ }^{1,4}$, Vincent

Lavoué $^{5,6}$, Philippe Descamps ${ }^{7}$, Alain Morel $^{1,3}$, Véronique Catros ${ }^{8}$, Guillaume Tcherkez ${ }^{9}$, Guy

Lenaers $^{10}$, Cinzia Bocca ${ }^{10}$, Judith Kouassi Nzoughet ${ }^{10}$, Vincent Procaccio ${ }^{10,11}$, Yves

Delneste $^{1,2, \|}$, Pascale Jeannin ${ }^{1,2, \|, *}$

${ }^{1}$ CRCINA, INSERM, Université de Nantes, Université d'Angers, Angers, France

${ }^{2}$ Laboratoire d'Immunologie et Allergologie, CHU d'Angers, Angers, France

${ }^{3}$ Institut de Cancérologie de 1'Ouest, Angers, France

${ }^{4}$ Service des Maladies du Sang, CHU d'Angers, Angers, France

${ }^{5}$ Service de Gynécologie-obstétrique, CHU de Rennes, Rennes, France

${ }^{6}$ UMR INSERM 1242, Université de Rennes, Rennes, France

${ }^{7}$ Département de Gynécologie, CHU d'Angers, Angers, France

${ }^{8}$ CHU de Rennes, Rennes, France; UMR INSERM 991, Rennes, France; CRB Santé de Rennes, Rennes, France

${ }^{9}$ Research School of Biology, ANU Joint College of Sciences, Australian National

University, Canberra, ACT, Australia

${ }^{10}$ Institut MitoVasc, Université d'Angers, UMR CNRS 6015 INSERM 1083, Angers, France

${ }^{11}$ Département de Biochimie et Génétique, CHU d'Angers, Angers, France

\# Equal contributions

॥ Joint supervision

* Corresponding author: Pascale Jeannin

CRCINA - Unité INSERM 1232, CHU d'Angers, 4 rue Larrey, 49933 Angers

pascale.jeannin@univ-angers.fr

Tel: +33 (0) 244688 311; fax: +33 (0) 244688594

Keywords: Macrophages, lactate, GM-CSF, M-CSF, inflammation, cancer 


\title{
Financial support
}

This work was supported by institutional grants from the University of Angers and Inserm and by grants from the Ligue contre le Cancer (comité du Maine et Loire, Angers, France) and the regional council of Pays de la Loire (Canceropole Grand-Ouest; projects PlasTICO and Concerto). Léa Paolini is supported by a grant from Angers Loire Métropole and Clément Adam is a recipient of a grant from the French Ministry of Higher Education and Research.

\section{Conflict of interest}

The authors declare no potential conflicts of interest

\section{Word count: 5500}

\section{Number of figures: 7}

\begin{abstract}
Abbreviations
EGFR, epidermal growth factor receptor; EMT, epithelial-mesenchymal transition; EREG, epiregulin; ET-1, endothelin 1; FOLR2, folate receptor beta; HB-EGF, heparin-binding epidermal growth factor-like; HGF, hepatocyte growth factor; $\mathrm{LDH}$, lactate dehydrogenase; MФ, macrophages; MCT, Monocarboxylate Transporter; Mo-DC, monocyte-derived dendritic cells; OSM, oncostatin M; PDGF-BB, platelet-derived growth factor B; SEPP1, selenoprotein P; SERPINB2, serpin family b member 2; TAM, tumor-associated macrophages; TGF $\alpha$, transforming growth factor $\alpha$; VEGF-A, vascular endothelial growth factor A.
\end{abstract}




\begin{abstract}
In established tumors, tumor-associated macrophages (TAMs) orchestrate non-resolving cancer-related inflammation and produce mediators favoring tumor growth, metastasis and angiogenesis. However, the factors conferring inflammatory and pro-tumor properties on human macrophages remain largely unknown. Most solid tumors have high lactate content. We therefore analyzed the impact of lactate on human monocyte differentiation. We report that prolonged lactic acidosis induces the differentiation of monocytes into macrophages with a phenotype including pro-tumor and inflammatory characteristics. These cells produce tumor growth factors, inflammatory cytokines and chemokines as well as low amounts of IL10. These effects of lactate require its metabolism and are associated with HIF- $1 \alpha$ stabilization. The expression of some lactate-induced genes is dependent on autocrine M-CSF consumption. Finally, TAMs with pro-tumor and inflammatory characteristics (VEGF ${ }^{\text {high }}$ $\mathrm{CXCL8}^{+} \mathrm{IL}_{1} \beta^{+}$) are found in solid ovarian tumors. These results show that tumor-derived lactate links the pro-tumor features of TAMs with their inflammatory properties. Treatments that reduce tumor glycolysis or tumor-associated acidosis may help combat cancer.
\end{abstract}




\section{Introduction}

Macrophages are involved in many physiological processes, including the maintenance of tissue homeostasis, antimicrobial defense and the control of immune responses (1). Macrophages detect diverse signals (e.g. microbes and cytokines) and sense changes in nutrient and oxygen availability. The phenotypes and functions of these cells continually adapting to tissue requirements (1-3), resulting in cellular diversity that complicates classification of macrophages (4). Classification of macrophages into M1 and M2 cells, corresponding to extremes of a continuum of phenotypes, is still widely used (4,5). M1 are tumoricidal cells that produce inflammatory and Th1-promoting cytokines and low concentrations of IL10. In contrast, M2 and M2-like cells have immunoregulatory and trophic properties and are involved in maintaining tissue homeostasis and orchestrating wound healing (2). Such cells produce high concentrations of IL10 and mediators involved in the recruitment of regulatory, Th2, and naive $\mathrm{T}$ cells, but produce only little Th1-promoting and inflammatory cytokines (6). Nevertheless, single-cell analysis has identified human macrophages with features of both M1 and M2 (7,8), particularly in established tumors (913). Most of the known macrophage polarization factors tend to antagonize their own effects rather than acting in an additive or synergistic manner. The polarization factors capable of generating human macrophages with mixed M1/M2 profiles therefore remain to be identified. Human and mouse macrophages differ in terms of differentiation and polarization factors and the expression of M1 and M2 markers (14-16). These differences make it impossible to extrapolate results obtained with mouse macrophages to human cells.

In most advanced solid tumors, tumor-associated macrophages (TAMs) constitute the largest infiltrating leukocyte population (17). Extensive TAM infiltration has been correlated with a poor prognosis in various cancers $(2,6)$. TAMs affect almost all aspects of tumor biology, as they promote angiogenesis, tumor progression, invasion and metastasis. This contribution to the various phases of tumor development highlights their functional diversity. Early in tumor development, macrophages have an anti-tumor M1 phenotype, due to the production of GMCSF and IFN $\gamma$ by activated leukocytes (6). Subsequent tumor growth then leads to the generation of signals perceived by monocytes/macrophages as indicating a need for tissue repair, resulting in the generation of TAMs with properties resembling those of M2 macrophages. Non-resolving chronic inflammation is a hallmark of carcinogenesis that contributes to the exhaustion and inefficiency of T cells. TAMs orchestrate tumor-associated 
inflammation $(6,18,19)$, suggesting that they may display both M2-like and M1-like features. However, the signals present in the tumor environment and involved in the acquisition of a mixed M1/M2 profile by TAMs remain unclear.

Most cancer cells sustain high rates of proliferation via aerobic glycolysis (Warburg effect) (20) and divert glucose-derived pyruvate away from the mitochondria toward lactate production. Lactate concentrations in normal tissues at rest are within the $1.8-2 \mathrm{mM}$ range, whereas lactate concentrations in solid tumors range from 6 to $15 \mathrm{mM}$, reaching $40 \mathrm{mM}$ in extreme cases (21). The export of lactate via lactate-proton symporters is accompanied by protons $\left(\mathrm{H}^{+}\right)$, the latter being responsible for the low extracellular $\mathrm{pH}$ in tumor tissues. Lactic acidosis is common in most solid tumors, and high concentrations of lactate are associated with aggressiveness and resistance to treatment (22). Lactate is not solely a by-product of glycolysis, but is also a fueling and signaling molecule, rescuing cancer cells from glucose deprivation (23). In an acidic extracellular milieu necessary for its cellular internalization, lactate may act as an immunoregulatory mediator. Lactate dampens cytotoxic T-cell and NK cell functions, favors Treg cell survival (24-27) and triggers the expression of M2 genes in murine macrophages (28-30).

The impact of chronic exposure to lactate on the differentiation of human monocytes remains to be determined. As TAMs are mostly derived from monocytes and lactic acidosis is a feature of tumors $(22,31)$, monocytes probably differentiate into TAMs in conditions of lactic acidosis. We report that lactate drives the differentiation of human monocytes into macrophages with an inflammatory and trophic phenotype similar to that of TAMs in ovarian tumors. 


\section{Materials and Methods}

\section{Monocyte isolation and cell generation}

Peripheral blood mononuclear cells (PBMC) were obtained from healthy human volunteers (Blood collection center, Angers, France; agreement ANG-2017-01) by standard densitygradient centrifugation on Lymphocyte Separation medium (Eurobio, Courtaboeuf, France). $\mathrm{CD}_{1}{ }^{+}$monocytes were then isolated by positive magnetic cell-sorting (Miltenyi Biotec, Bergisch Gladbach, Germany); purity was routinely $>98 \%$. Monocytes $\left(1 \times 10^{6}\right.$ cells $\left./ \mathrm{mL}\right)$ were cultured for 5 days in complete medium (CM) consisting in RPMI 1640 (Lonza, Verviers, Belgium) supplemented with 10\% FCS (Eurobio), $2 \mathrm{mM}$ L-glutamine, $1 \mathrm{mM}$ sodium pyruvate, $0.1 \mathrm{mM}$ nonessential amino acids, $10 \mathrm{mM}$ Hepes, penicillin (100 U/mL) and streptomycin $(100 \mu \mathrm{g} / \mathrm{mL}$, all from Lonza) in the presence of M-CSF (50 ng/mL, ORF Genetics, Kopavogur, Iceland) to generate M-MФ, or GM-CSF (50 ng/mL, R\&D Systems, Lille, France) to generate GM-MФ. Prototypic M2 cells (M+IL4-M $\Phi$ ) were generated by culturing monocytes in CM medium containing M-CSF (50 ng/mL) for 5 days, with the addition of IL4 (50 ng/mL, R\&D Systems) at day 3. Monocyte-derived dendritic cells (MoDC) were generated by culturing monocytes for 5 days with GM-CSF (50 ng/mL) and IL4 (50 $\mathrm{ng} / \mathrm{mL}$ ) in $\mathrm{CM}$ medium.

\section{Lactic acidosis, acidosis, and lactosis}

Monocytes $\left(1 \times 10^{6}\right.$ cells $\left./ \mathrm{mL}\right)$ were differentiated under lactic acidosis by culture for 5 days in CM with $50 \mathrm{ng} / \mathrm{mL}$ GM-CSF and $10 \mathrm{mM}$ lactate (Sigma-Aldrich, St Louis, MO) with a resulting $\mathrm{pH}$ of 6.5 . In some experiments, $2-40 \mathrm{mM}$ lactate were used. In others, monocytes were cultured for 5 days in CM with GM-CSF plus $10 \mathrm{mM}$ lactate in the presence of $3 \mu \mathrm{M}$ GW2580, $125 \mu \mathrm{M} \alpha$-cyano-4-hydroxycinnamate (CHC), $1 \mu \mathrm{M}$ acriflavine, $5 \mathrm{mM}$ oxamic acid (all from Sigma-Aldrich), 15 MM GSK2837808A (Tocris, Lille, France), neutralizing anti-MCSF ( $4 \mu \mathrm{g} / \mathrm{mL})$ or isotype control mAbs $(4 \mu \mathrm{g} / \mathrm{mL}$, both from R\&D Systems), or $1.25 \mu \mathrm{M}$ AZD3965 (Cayman Chemical, Ann Arbor, MI). All inhibitors were used at the highest nontoxic concentration (Supplementary Table S1). Monocytes were differentiated under acidosis by culture for 5 days in CM containing GM-CSF plus $12.35 \mathrm{mM} \mathrm{HCl}$ to reach a final $\mathrm{pH}$ of 6.5. Monocytes were differentiated under lactosis by culture for 5 days in $\mathrm{CM}$ containing GM-CSF plus $10 \mathrm{mM}$ sodium lactate (Sigma-Aldrich) (pH=7.3). 


\section{Cytokine quantification}

Cells were counted by flow cytometry using 123count eBeads (Thermo Fisher Scientific) after staining with 7-AAD or LIVE/DEAD Fixable Near-IR Dead Cell Stain Kit (Molecular Probes, Carlsbad, CA) to discriminate dead cells from living cells at the end of the 5-7 days culture. Macrophages $\left(0.5 \times 10^{6}\right.$ living cells $\left./ \mathrm{mL}\right)$ were stimulated with $200 \mathrm{ng} / \mathrm{mL}$ LPS (from E. coli serotype O111:B4; Sigma-Aldrich) in fresh CM (to avoid interference in cytokine quantification due to acidic $\mathrm{pH}$ ). Cytokines were quantified in the $24 \mathrm{~h}$ cell culture supernatants by fluorescent-bead-based multiplex immunoassay (R\&D System), except IL12p70 (Diaclone; Dijon, France), endothelin-1 and IL20 (both from R\&D Systems) which were quantified using conventional ELISA; IL20 was quantified in 5-fold concentrated supernatants using Amicon Ultra centrifugal filters (Merck Millipore, Burlington, MA). Soluble CD115 (sCD115) and M-CSF were quantified by ELISA (R\&D Systems) in the supernatants of monocytes cultured without or with $10 \mathrm{mM}$ lactate; lactate did not interfere with CD115 and M-CSF quantification (not shown).

\section{Flow cytometry analysis}

In order to discriminate dead cells from living cells, all samples were stained with LIVE/DEAD Fixable Near-IR Dead Cell Stain Kit (Molecular Probes) before flow cytometry analysis using mAbs to CD1a, CD14, CD163 or CD115. Intracellular cytokine and pERK1/2 expression was evaluated on day-5 macrophages stimulated for $24 \mathrm{~h}$ with LPS (in the presence of monensin for the last $6 \mathrm{~h}$; BD Bioscience) or on dissociated ovarian cancer cells stimulated or not for $6 \mathrm{~h}$ with $50 \mathrm{ng} / \mathrm{mL}$ LPS (in the presence of monensin). Briefly, cells were fixed (4\% PFA in PBS) and permeabilized (0.1\% saponin in PBS containing $0.1 \%$ BSA) before incubation with mAbs to TNF $\alpha$ and -IL6. The expression of IL1, CXCL8, and VEGF was also evaluated in activated ovarian cancer TAM. After mechanical and enzymatic dissociation, cells were stimulated, or not, for $6 \mathrm{~h}$ with $50 \mathrm{ng} / \mathrm{mL}$ LPS in the presence of monensin. After membrane permeabilization, cells were incubated with anti-IL1 $\beta$, antiCXCL8, anti-VEGF or anti-CD14 and related control mAbs (all from BioLegend, San Diego, CA). Data were acquired using a FACSCanto II flow cytometer (BD Biosciences, San Jose, CA) and analyzed with the FlowJo software (Tree Star, Ashland, OR). Results are expressed as relative of fluorescence intensity (RFI) defined as the ratio of specific fluorescence (MFI values with specific mAb) over non-specific fluorescence (MFI values with isotype control mAbs) or as a percentage of labeled cells. Antibodies are listed in Supplementary Table S2. 


\section{Analysis of mRNA}

Total RNA was extracted and reverse-transcribed as previously described (32), and the amounts of mRNA for the proteins indicated were evaluated by qPCR. Relative quantification was performed by the $2^{-\Delta \Delta C T}$ method, using RPS18, EF1A, TBP, RPL13A, and PPIA as references (33). This method of calculation is based on the conversion of linear Cq values onto a logarithmic scale, with PCR efficiency as an exponential function; the geometric mean values of mRNA amounts for selected housekeeping genes is used as a normalization factor, making it possible to eliminate intersample variation.

\section{Lactate and glucose quantification}

Glucose and lactate concentrations in cell culture supernatants were determined using enzymatic assays (Abcam, Cambridge, UK) according to the manufacturer's instructions. Results are expressed in $\mathrm{mmol} / \mathrm{L}$ or as a rate $(\mathrm{mmol} / \mathrm{L} / 24 \mathrm{~h})$ of consumption or production (concentration values divided by the number of days of culture), with positive and negative values corresponding to consumption and production, respectively.

\section{Analysis of lactate metabolism}

In order to monitor extracellular lactate metabolism, monocytes were differentiated for 5 days with $50 \mathrm{ng} / \mathrm{mL}$ GM-CSF plus $10 \mathrm{mM}{ }^{13} \mathrm{C}$-lactate sodium (Sigma-Aldrich), $\mathrm{pH}=6.5 .{ }^{13} \mathrm{C}$ containing metabolites present in day-5 cell culture supernatants and cell extracts were analyzed by NMR spectroscopy and liquid chromatography coupled to high-resolution mass spectrometry (LC-MS), respectively.

Freeze-dried supernatants were lyophilized and dissolved in $500 \mu \mathrm{L}$ maleate-EDTA buffer (12.5 mM EDTA, $250 \mathrm{mM}$ maleate, $\mathrm{pH}=7)$ and $50 \mu \mathrm{L}$ heavy water $\left(\mathrm{D}_{2} \mathrm{O}\right.$; Sigma-Aldrich). After centrifugation $\left(7,500 \times \mathrm{g}, 3 \mathrm{~min}, 15^{\circ} \mathrm{C}\right)$, samples were transferred into a 5 -mm tube (Z107373; Bruker Biospin, Alexandria, NSW, Australia) before analysis with a NMR spectrometer Advance $700 \mathrm{Mz}$ (Bruker Biospin). NMR analyzes were performed at $298 \mathrm{~K}$ $\left(25^{\circ} \mathrm{C}\right)$ without tube spinning, using a proton-decoupled carbon pulse program (zgig) with $90^{\circ}$ pulses $(10 \mu \mathrm{s}, 50 \mathrm{~W})$. Acquisition parameters: decoupling sequence waltz16, $0.9 \mathrm{~s}$ acquisition time, $65 \mathrm{k}$ size of FID, and a relaxation delay (D1) of $1.2 \mathrm{~s} .12,500$ scans were done, representing about $10 \mathrm{~h}$ analysis per sample. ${ }^{13} \mathrm{C}$-quantitation was performed by peak integration with TopSpin $3.5 \mathrm{pl} 7$ using maleate (125 $\mu$ mol per sample) as an internal standard. 
Frozen cell pellets were resuspended in cold methanol $(\mathrm{MeOH})$ and vortexed for 1 min. Samples were extracted with $\mathrm{MeOH}$ :acetonitrile: $\mathrm{H}_{2} \mathrm{O}(2: 2: 1$; v:v) and the mixture was then vortexed for $30 \mathrm{sec}$ and centrifuged $\left(8,000 \times \mathrm{g}, 10 \mathrm{~min}, 4^{\circ} \mathrm{C}\right)$. The resulting supernatant was evaporated to dryness using a miVac duo concentrator (Genevac Ltd, Ipswich, UK). The dry extract was reconstituted with $200 \mu \mathrm{L}$ of a solution of $2 \%$ aqueous $\mathrm{MeOH}$ (initial conditions of the chromatographic elution gradient) and subjected to a second centrifugation $(8,000 \times \mathrm{g}$, $10 \mathrm{~min}, 4^{\circ} \mathrm{C}$ ) prior to mass spectrometry analysis. The analytical system was based on a reverse phase ultra-high-performance liquid chromatography (UPLC) (Dionex ${ }^{\mathrm{TM}}$ UltiMate 3000; Thermo Scientific, Waltham, MA) coupled to a high-resolution mass spectrometer (LCMS) (Q Exactive ${ }^{\mathrm{TM}}$; Thermo Scientific). LC-MS analysis was performed according to a recently validated method (33). Results are expressed as a percentage of redistribution of ${ }^{13} \mathrm{C}$ into metabolites present in the day-5 cell culture supernatants (RMN) or isotopic enrichment in each molecule taken individually in day-5 cell lysates (LC-MS).

\section{Measurements of oxygen consumption rate}

The XF96 extracellular flux analyzer (Seahorse analyzer; Agilent Technologies, Santa Clara, CA) was used to determine the bioenergetic profile of macrophages. Day-5 cells were seeded $\left(50 \times 10^{3}\right.$ cells/well) in XF96 plates and allowed to recover for $24 \mathrm{~h}$. Cells were then incubated in bicarbonate-free DMEM (Sigma-Aldrich) supplemented with $11 \mathrm{mM}$ glucose, $2 \mathrm{mM} \mathrm{L}$ glutamine and $1 \mathrm{mM}$ sodium pyruvate in a $\mathrm{CO}_{2}$-free incubator for $1 \mathrm{~h}$. The oxygen consumption rate (OCR) was recorded to assess the mitochondrial respiratory activity and glycolytic activity. After measurements under basal conditions, cells were treated sequentially with $2 \mu \mathrm{g} / \mathrm{mL}$ oligomycin and $3 \mu \mathrm{M}$ carbonyl cyanide $\mathrm{p}$-(trifluoromethoxy) phenylhydrazone (FCCP; Sigma-Aldrich). Non mitochondrial respiration (OCR value after addition of $1 \mu \mathrm{g} / \mathrm{mL}$ antimycin A) was subtracted from all OCR measurements. ATP-linked respiration was estimated from the difference between the basal and the oligomycin-inhibited respiration, proton-leak respiration is obtained by subtracting non-mitochondrial respiration from the oligomycin rate and the maximal respiratory capacity was the rate in the presence of the uncoupler FCCP. Three independent replicates of each measurement were generated, and results were normalized according to cell concentrations.

\section{Coculture assay}

In order to evaluate the impact of tumor cell-derived lactate on the phenotype of macrophages, monocytes were co-cultured with the primary tumor cells CASC170, CKC0829 
and CKT0151 cells isolated from patients with primary ovarian cancer peritoneal carcinosis (Biological resource center, University Hospital of Rennes, Rennes, France; agreement BB0033-00056) and selected on their capacity to produce lactate (Supplementary Fig. S1); cells were negative for mycoplasma. Monocytes were co-cultured with the tumor cells using 12well Transwell units with $0.4 \mu \mathrm{m}$ diameter pore size polycarbonate filters (Corning, New York, NY). Monocytes $\left(1 \times 10^{6}\right.$ cells $\left./ \mathrm{mL}\right)$ were seeded in the lower compartment containing 50 $\mathrm{ng} / \mathrm{mL}$ GM-CSF, in the absence or presence of $\mathrm{CHC}$, and $2.5 \times 10^{4}$ tumor cells were added in the upper part of the Transwell. After 5 days, macrophages were analyzed by flow cytometry and by qPCR. In some experiments, macrophages were washed and counted $\left(0.5 \times 10^{6}\right.$ living cells/mL in fresh CM) before stimulation with $200 \mathrm{ng} / \mathrm{mL}$ LPS for cytokine quantification.

\section{Statistical analysis}

Statistical analyses were performed with Prism 7 (GraphPad Software Inc., La Jolla, CA).

Non-parametric Wilcoxon matched-pairs tests were used to compare means. For the comparison of antigen expression time courses, two-way analysis of variance (ANOVA) was performed, with Bonferroni post hoc correction for multiple comparisons. Values of $p<0.05$ were considered statistically significant. 


\section{Results}

\section{Lactic acidosis leads to generation of $\mathrm{CD} 14^{\text {high }} \mathrm{CD} 163^{\text {high }}$ macrophages in humans}

GM-CSF is overproduced at tumor sites and enables human monocytes to survive and differentiate into macrophages (15). We assessed the impact of lactic acidosis on monocyte differentiation by culturing human monocytes with GM-CSF, with or without lactate, and analyzing their phenotype on day 5 . We used $10 \mathrm{mM}$ lactate for these experiments, as, consistent with the findings of a previous study (34), this was the highest nontoxic concentration for human monocytes/macrophages (Fig. 1A) and is the concentration found at tumor sites (27).

Under conditions of lactic acidosis (10 $\mathrm{mM}$ lactate, $\mathrm{pH}=6.5)$, monocytes differentiated into macrophages (GM+LA-M $\Phi)$, as demonstrated by the expression of the macrophage markers CD14 and CD163, but not of the Mo-DC marker CD1a (Fig. 1B and C). CD14 and CD163 were more strongly expressed on GM+LA-M $\Phi$ than on GM-M $\Phi$, as reflected in both protein (Fig. 1C) and mRNA content (Fig. 1D). Expression of CD163 was upregulated in a timedependent manner during differentiation (Fig. 1E). As previously reported (35), M-MФ also had a CD14 ${ }^{\text {high }}$ CD $163^{\text {high }}$ phenotype (Fig. 1B-E).

\section{The effects of lactate depend on its entry into cells}

Lactic acidosis results from extracellular accumulation of lactate and protons, leading to a lowering of extracellular $\mathrm{pH}$ (27). We therefore evaluated whether the effects of lactate on monocytes/macrophages were due to an adaptation to acidosis or to lactosis. The differentiation of monocytes under conditions of acidosis (12.35 mM HCl, $\mathrm{pH}=6.5)$ or lactosis (10 mM sodium lactate, $\mathrm{pH}=7.3$ ) had no effect on the expression of CD163 and CD14 on macrophages on day 5 (Fig. 2A, left panels).

Lactate import into cells is mediated by monocarboxylic acid transporters (MCT) and requires a low extracellular $\mathrm{pH}$ (28). As both lactosis and a low $\mathrm{pH}$ were required for the conversion of GM-M $\Phi$ into $\mathrm{CD} 163^{\text {high }} \mathrm{CD} 14^{\text {high }}$ cells, we hypothesized that this process was dependent on lactate influx into cells. Consistent with this hypothesis, the MCT inhibitor CHC (used at 125 $\mu \mathrm{M}$; (28)) and the specific MCT1 inhibitor AZD3965 (used at 1.25 $\mu \mathrm{M}$; (36)) prevented lactate from upregulating the expression of CD14 and CD163 (Fig. 2A), suggesting that the impact of lactate on macrophage polarization resulted from its uptake into cells. MCT 
inhibitors blocked lactate influx and efflux (Supplementary Fig. S2A). We then formally demonstrated lactate entry and metabolism by macrophages, with ${ }^{3} \mathrm{H}$-labeled and ${ }^{13} \mathrm{C}$-labeled lactate. Results showed that the internalization of ${ }^{3} \mathrm{H}$-labeled lactate by differentiating GM+LA-M $\Phi$ was reduced in the presence of CHC (Supplementary Fig. S2B). NMR spectroscopy and LC-MS revealed the presence of ${ }^{13} \mathrm{C}$-metabolites in GM+LA-M $\Phi$ and culture supernatants, with malate, alanine and glutamate being the most abundant of these metabolites (Fig. 2B). We also quantified glucose and lactate in the supernatants of GM-MФ and GM+LA-M $\Phi$ during differentiation (Supplementary Fig. S2C). As expected (37), GMMФ consumed glucose and released lactate. GM+LA-M $\Phi$ were less glycolytic and consumed less glucose than GM-MФ (Supplementary Fig. S2C). For GM+LA-M $\Phi$, extracellular lactate corresponded to nonconsumed exogenous lactate and endogenous lactate released by glycolysis. Consistent with the observations reported above, extracellular lactate quantification at day 3 showed a consumption of exogenous lactate by GM+LA-MФ (Supplementary Fig. S2C). Finally, mitochondrial respiration analyses showed less electron chain activity in GM+LA-MФ than in GM-MФ (37), although the mitochondria remained functional in both (Supplementary Fig. S2D).

Our data therefore show that (i) the increase in CD14 and CD163 expression induced by lactate depends on lactate uptake into cells and (ii) the lactate taken up is metabolized by human macrophages.

\section{GM+LA-MФ have a non-Th1-promoting inflammatory phenotype}

Damage-associated molecules signaling via TLR4 accumulate in tumors (38). We therefore analyzed the cytokine profile of GM+LA-M $\Phi$ in response to the prototypic TLR4 agonist LPS.

As expected (35,39), LPS-stimulated GM-MФ had an IL10 ${ }^{\text {low }}$ IL12p70 ${ }^{\text {high }}$ M1-type phenotype and produced large amounts of inflammatory cytokines (Fig. 3A). Stimulated GM+LA-M $\Phi$ produced much more IL1 $\beta$, IL6, TNF $\alpha$ and CXCL8 than stimulated GM-M $\Phi$, but only small amounts of IL10 (Fig. 3A). The upregulation of IL6 and TNF $\alpha$ production by GM+LA-MФ was homogeneous in the cells of the $\mathrm{CD} 14^{\text {high }} \mathrm{CD} 163^{\text {high }}$ population; we therefore excluded the possibility that the IL6 ${ }^{\text {high }} \mathrm{TNF} \alpha^{\text {high }}$ phenotype resulted from coexistence of different cell subpopulations (Fig. 3B). GM+LA-M , with and without stimulation, upregulated transcripts encoding IL1 $\beta$, TNF $\alpha$, and IL6, and several chemokines, including CCL2, CCL13, and 
CXCL5 (involved in myeloid cell recruitment); CXCL8 (involved in neutrophil recruitment), and CXCL2 and CXCL3 (which favor angiogenesis) (Fig. 3C). Most of these chemokines are present at tumor sites and are associated with a poor prognosis (40).

Unlike GM-MФ, GM+LA-M $\varphi$ produced low amounts of the Th1-inducing factor IL12p70 and did not produce the Th1-attracting chemokine CXCL10 (Fig. 3A). Consistent with this finding, DCs generated in the presence of lactate are also unable to produce IL12 (24). GM+LA-MФ also produced larger amounts of CXCL1 and CCL18 (involved in the recruitment of immunosuppressive myeloid cells) and of CCL24 (involved in naive and resting T-cell recruitment) than GM-MФ (Fig. 3C).

The capacity of lactate to induce IL $1 \beta^{\text {high }}$ IL12 ${ }^{\text {low }}$ macrophages was dependent on its entry into cells, as this induction was prevented by MCT inhibitors (Fig. 2A) and not mimicked by acidosis. Indeed, consistent with previous studies $(41,42)$, monocyte differentiation under acidosis conditions increased the capacity of the resulting macrophages to secrete IL12p70 and IL1 $\beta$, albeit to a lesser extent than in the presence of lactate (Fig. 2A). Finally, lactosis did not affect the secretion of IL1 $\beta$ and IL12p70 by macrophages (Fig. 2A).

Collectively, these results show that lactate induces pro-inflammatory macrophages (i.e. nonpro-Th1), a phenotype compatible with chronic inflammation and an ineffective adaptive immune response, as observed in established tumors (6).

\section{Lactic acid-induced macrophages secrete tumor-promoting factors}

TAMs are a source of growth factors (6). We therefore evaluated the capacity of GM+LA$\mathrm{M} \Phi$ to produce pro-tumor factors. GM+LA-M $\varphi$ produced larger amounts of transcripts than GM-MФ, for (i) the EGFR ligands HB-EGF, TGF $\alpha$, and epiregulin; (ii) the epithelial growth factors HGF and IL20; (iii) the epithelial-mesenchymal transition factor OSM; and (iv) the endothelial and mesenchymal cell proliferation and migration factors VEGF-A and PDGF-BB (Fig. 4A). Accordingly, stimulated GM+LA-MФ produced larger amounts of HB-EGF, TGF $\alpha$, IL20, OSM, VEGF-A, and ET-1 than GM-MФ (Fig. 4B). Most of these factors are expressed by TAMs in established tumors and are associated with tumor growth and metastasis (43). 
This pro-tumor signature induced by lactate was different from that of prototypic M2 and M2-

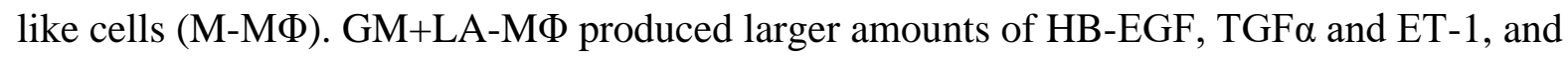
smaller amounts of VEGF-A than M2 and M2-like cells (Fig. 4B). Moreover, the amounts of most of the M2 transcripts induced by IL4 (44) were not upregulated by lactate (Supplementary Fig. S3).

Thus, lactate promotes the generation of macrophages with a phenotype combining inflammatory and tumor-trophic features.

\section{Lactic acid enhances autocrine M-CSF consumption by differentiating myeloid cells}

$\mathrm{GM}+\mathrm{LA}-\mathrm{M} \varphi$ displayed upregulation of several mRNAs, including those encoded by SERPINB2, FOLR2, SEPP1 and CD163, which are defined as M-CSF-induced genes (Fig. 5A and B) (39). Consistent with the findings of studies showing that GM-CSF, by downregulating CD115 expression, limits M-CSF consumption and, consequently, the expression of M-CSFinduced genes by monocytes (35,45-47), we observed an accumulation of autocrine M-CSF in the culture supernatants of GM-M $\Phi$ (Fig. 5C).

Based on these observations, we hypothesized that lactate might promote the consumption of autocrine M-CSF by differentiating MФ. This hypothesis is supported by various lines of evidence. First, unlike GM-M $\Phi$, GM+LA-M $\Phi$ displayed (i) an early increase in CD115 mRNA amounts (Supplementary Fig. S4A), (ii) an increase in membrane CD115 expression at $6 \mathrm{~h}$ and $24 \mathrm{~h}$ (followed by a return to amounts similar to those in GM-MФ at $48 \mathrm{~h}$ ) (Fig. 5D, left panel) and, (iii) a decrease in sCD115 release (Fig. 5D, right panel), whereas total CD115 expression remained unchanged (Supplementary Fig. S4B). Second, M-CSF mRNA amounts increased in GM+LA-MФ Supplementary Fig. S4A) whereas M-CSF remained undetectable in the culture supernatants of these cells (Fig. 5C). Third, the CD115 tyrosine kinase inhibitor GW2580 (48), and a neutralizing anti-M-CSF (49), but not a control mAb, prevented the induction of $\mathrm{CD} 163^{\text {high }} \mathrm{CD} 14^{\text {high }}$ macrophage production by lactate (Fig. 5E). GW2580 also decreased the expression of the M-CSF-dependent genes SERPINB2, FOLR2, SEPP1 and CD163 (Fig. 5B) and the secretion of VEGF-A and TGF $\alpha$ by GM+LA-M $\Phi$ (Fig. 5F). Fourth, flow cytometry revealed that the amount of ERK1/2 phosphorylation, which is induced by MCSF and lactate (50), was higher in GM+LA-MФ than in GM-M $\Phi$ (Supplementary Fig. S4C). 
Although M-MФ are not inflammatory cells (39), we observed that the acquisition of an inflammatory signature was dependent on autocrine consumption of M-CSF during the differentiation process (as illustrated by the decrease in IL1 $\beta$ and TNF $\alpha$ production by GM+LA-MФ in the presence of GW2580; Fig. 5F). However, consistent with our observations, macrophages generated by incubation with GM-CSF, M-CSF, and IL6 (GM+M-

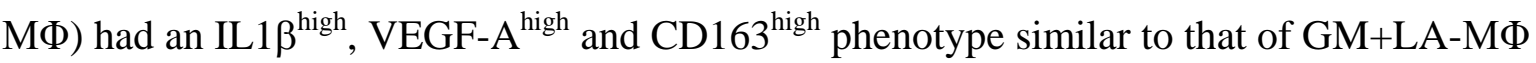
(Supplementary Fig. S4D). This result is consistent with IL6 unlocking M-CSF consumption by myeloid cells $(35,45)$. Finally, the phenotype of GM+LA-MФ cannot be entirely due to the consumption of M-CSF. First, GW2580 did not modulate the secretion of OSM, HB-EGF, IL12p70, or CXCL10 by GM+LA-MФ (Supplementary Fig. S4E). Second, GM+M-MФ produced smaller amounts of HB-EGF than GM+LA-MФ (Supplementary Fig. S4D). Third, in the absence of GM-CSF, we detected no effect of lactate when monocytes were differentiated in the presence of M-CSF (Supplementary Fig. S3).

In conclusion, lactate induces the autocrine consumption of M-CSF by monocytes exposed to GM-CSF and this mechanism may explain the acquisition of certain inflammatory and trophic features.

\section{Acquisition of GM+LA-MФ phenotype is dependent on lactate metabolism}

Lactate inhibits cytoplasmic prolyl hydroxylases, which degrade the transcription factor HIF$1 \alpha$ (51). Accordingly, lactate increases the expression of M2 genes by murine macrophages through the stabilization of HIF-1 $\alpha$ (28). Consistent with this result, we observed that the HIF$1 \alpha$ inhibitor acriflavin (52) decreased the lactate-induced synthesis of M-CSF mRNA and, as previously reported in mice (53), of CD115 mRNA (Fig. 6A), supporting a role for HIF1- $\alpha$ in autocrine M-CSF consumption by human GM+LA-MФ. Acriflavin also prevented upregulation of CD14 and CD163 (Fig. 6B) and of M-CSF-dependent marker expression (Fig. 6C), and production of IL1 $\beta$, TNF $\alpha$, HB-EGF and OSM as induced by lactate (Fig. 6D).

Stabilization of HIF-1 $\alpha$ induced by lactate requires lactate oxidation to pyruvate (54-56). Consistent with these studies, the LDH inhibitors oxamic acid and GSK2837808A prevented lactate from increasing CD163 and CD14 expression and IL1 $\beta$ and HB-EGF production by GM+LA-MФ (Fig. 6E). 
Thus, the acquisition of the GM+LA-M $\Phi$ phenotype by monocytes is dependent on lactate metabolism and HIF-1 stabilization.

\section{Ovarian tumor TAMs have a pro-inflammatory trophic phenotype}

We evaluated the effect of tumor-derived lactate on monocyte differentiation, by culturing monocytes with lactate-producing primary ovarian tumor cells (Supplementary Fig. S1A). Macrophages generated in the presence of these tumor cells had high amounts of CD163, CD14 and IL1 $\beta$ (Fig. 7A and Supplementary Fig. S1B) and of SEPP1, FOLR2, STAB1, EREG, and OSM (Fig. 7B). These effects were prevented by CHC (Fig. 7A and B and Supplementary Fig. S1B). CKC829 and CKT151 cell lines (which produce IL6 and M-CSF in addition to lactate) induced a more pronounced expression of the M2-like marker CD163 on macrophages than CASC170 cells, reinforcing the involvement of M-CSF and IL6 in the acquisition of M2-like features by human macrophages generated under lactic acidosis (Supplementary Fig. S1A).

We then investigated whether the TAMs in solid ovarian tumors had a phenotype similar to that of GM+LA-MФ. We monitored the amounts of (i) VEGF, as VEGF ${ }^{\text {high }}$ TAMs are located in lactate-rich zones $(29,57)$ and (ii) the inflammatory cytokines CXCL8 and IL1 $\beta$ in LPSstimulated cell suspensions (obtained after tumor dissociation). We detected three subsets of CD14 ${ }^{+}$cells: CXCL8 ${ }^{-} \mathrm{IL}_{1} \beta^{-} \mathrm{VEGF}^{+}, \mathrm{CXCL}^{+} \mathrm{IL} \beta^{-} \mathrm{VEGF}^{+}$and $\mathrm{CXCL}^{+} \mathrm{IL} \beta^{+} \mathrm{VEGF}^{+}$(Fig. $^{-}$ 7C). VEGF concentrations were highest in TAMs producing CXCL8 and IL1 $\beta$ (Fig. 7D), as observed in GM+LA-M $\Phi$ (Fig. 5F).

Collectively, these results demonstrate the existence of human TAMs with protumor and inflammatory features in ovarian tumors and highlight the role of tumor-derived lactate in their generation (Supplementary Fig. S5). 


\section{Discussion}

Most of the known macrophage-polarizing factors give rise to either trophic (M2) or inflammatory (M1) cells (5). Nevertheless, macrophages displaying both M1- and M2-like features have been reported in various situations, including cancer $(12,13)$. We show here that prolonged exposure to lactate, which is produced in large amounts in tumors $(21,27)$, confers on human macrophages a phenotype combining inflammatory and pro-tumor features. The acquisition of this phenotype required the internalization and metabolism of lactate and was dependent on HIF-1 stabilization and, for some factors, on M-CSF consumption. These results identify tumor-derived lactate as a missing link reconciling the M2-like features of human TAMs with their inflammatory properties.

We report that GM+LA-M $\Phi$ produce numerous growth factors promoting tumor cell proliferation, migration and invasion and that this profile more closely resembles that of macrophages generated with M-CSF $(5,39)$ than that of prototypic M2 cells generated with IL4 or IL13 (44). Accordingly, lactate has been reported to upregulate the expression of M2type genes in mouse macrophages, independently of IL4 (28). Furthermore, M-CSF is overproduced in numerous solid tumors (58-60), whereas IL4 and IL13 are detected in a limited number of cancers $(4,61)$. In addition to having trophic properties, TAMs contribute to persistent inflammation (6) and also promote immune suppression $(5,62,63)$. We show that GM+LA-M $\Phi$ have an inflammatory phenotype, as illustrated by their secretion of inflammatory cytokines and chemokines. The cytokine profile of GM+LA-M $\Phi$ suggests that they have the ability to subvert antitumor immune responses. They produce small amounts of CXCL10 and IL12, which are involved in the recruitment of $\mathrm{CD}^{+} \mathrm{T}$ cells and the generation of Th1 cells (40), respectively. Moreover, they produce high amounts of cytokines that favor the local accumulation of immunosuppressive myeloid cells (such as CXCL1) and of naive T cells (CCL18 and CCL24) that ultimately, differentiate into Treg cells $(64,65)$. They also produce M-CSF that promotes monocyte recruitment and differentiation into regulatory M2like cells (35).

We show that GM+LA-M $\Phi$ acquire most of their characteristics through the autocrine consumption of M-CSF, which is regulated in human myeloid cells. For example, M-CSF accumulates in the cell culture supernatants of DCs and M1-like macrophages $(35,45,66)$ and its consumption is induced by IL6 in differentiating cells $(35,45,67)$. Our results show that 
lactate also triggers M-CSF consumption by increasing the expressing of M-CSF and CD115, decreasing sCD115 release and increasing CD115 downstream signaling. GM-CSF induces IL10 ${ }^{\text {low }}$ IL1 $\beta^{\text {high }} \mathrm{TNF}^{\text {high }}$ cells, whereas M-CSF induces anti-inflammatory IL10 ${ }^{\text {high }}$ IL1 $\beta^{\text {low }}$ $\mathrm{TNF} \alpha^{\text {low }}$ cells $(35,39,68)$. As M-M $\Phi$ are anti-inflammatory cells, we hypothesized that lactate would attenuate the inflammatory phenotype of GM-MФ. However, GM+LA-M $\Phi$ actually had a more pronounced inflammatory phenotype than GM-MФ. This observation can be explained by the induction of M-CSF consumption by IL6, increasing the capacity of macrophages to produce pro-inflammatory cytokines. Consistent with this hypothesis, in situations of chronic inflammation, M-CSF exacerbates rather than attenuates inflammation $(15,69,70)$. Nevertheless, the phenotype of GM+LA-MФ differs from that of GM+M-MФ, confirming that the acquisition of this phenotype results from the integration of different signals.

The impact of lactate on macrophage differentiation is dependent on its internalization and metabolism, and requires HIF-1 stabilization. In murine macrophages, the expression of CD115 (53) and the induction of the M2 genes Arg1 and VEGF by lactate (28) depend on HIF-1 stabilization. As HIF-1 induces expression of the IL1 $\beta$ and IL6 genes (71), its stabilization can also directly induce an inflammatory phenotype in GM+LA-MФ. Accordingly, the phenotype of GM+LA-MФ was not induced by lactosis or acidosis. Lactate decreased the amount of IL12 production, but, as in other studies (41), we found that acidosis increased IL12 secretion by human myeloid cells. Acidosis also increased IL1 $\beta$ secretion by macrophages, but to a lesser extent than lactate.

Our results, together with published results for studies in mice (28-30), highlight the role of tumor-derived lactate in shaping the phenotype of human and mouse TAMs. We show that tumor-derived lactate induces the production of inflammatory pro-tumor macrophages in the presence of oxygen. VEGF ${ }^{\text {high }}$ TAMs have been reported to be localized in ischemic zones, characterized by hypoxia and high concentrations of lactate $(29,57)$. Hypoxia acts in synergy with lactate to induce pro-angiogenic pro-tumor TAMs $(28,29)$, but hypoxia alone does not skew murine TAMs towards a tumor-promoting phenotype (30,72). In addition, the ERK1/2 pathway, which is involved in the CD115-induced signaling, can also be activated by lactate and hypoxia (50), highlighting the additive/synergistic impact of different differentiation signals in ischemic areas. These studies and our results confirm that lactate is a tumor-derived metabolite playing a role in the induction of TAMs. Finally, we report that TAMs in solid 
ovarian tumors are functionally heterogeneous, with some expressing an inflammatory and protumor phenotype (IL1 $\beta^{+} \mathrm{CXCL}^{+} \mathrm{VEGF}^{+}$); these TAMs, with a phenotype resembling that of GM+LA-M $\Phi$, are probably located in or near ischemic zones in ovarian cancers.

The crosstalk between lactate, M-CSF and GM-CSF may affect cancer treatment. In the early stages of tumor development, GM-CSF participates in antitumor immune surveillance by inducing antitumor macrophages (73). By contrast, in advanced tumors, the amounts of GMCSF and M-CSF increase, and high amounts of GM-CSF or M-CSF are associated with poor prognosis and metastasis (15). GM-CSF then favors the recruitment and accumulation of immunosuppressive myeloid cells and its neutralization reduces tumor growth (74-77). Similarly, M-CSF promotes monocyte recruitment and differentiation into M2-like cells $(58,78)$. The ability of lactate to induce, in the presence of GM-CSF, the consumption of MCSF by monocytes/macrophages suggests that the lactate secreted by growing tumors in vivo switches monocyte differentiation from M1 cells to inflammatory and trophic TAMs. This helps explain the antagonistic roles of GM-CSF at different stages of tumor development (Supplementary Fig. S5). Finally, as M-CSF and lactate act together to shape the phenotype of human TAMs in established tumors, combination treatments aiming to decrease tumor cell glycolysis and to neutralize M-CSF/CD115 could work synergistically to re-educate TAMs and direct them against tumors.

In conclusion, we demonstrate that lactate confers a pro-tumor and inflammatory phenotype on human macrophages, underlining its role in inducing persistent and unresolved cancerrelated inflammation and sustaining tumor growth, without initiating an effective anti-tumor immune response. These observations highlight the potential therapeutic value of drugs that decrease tumor glycolysis as a means of reprogramming TAMs to boost the efficacy of immunotherapies. 


\section{Acknowledgments}

The authors acknowledge Muriel Gervois (University Hospital of Rennes, Rennes, France), Catherine Guillet and Jérome Cayon (PACeM facility; University of Angers) for expert technical assistance. This work was realized in the context of the LabEX IGO program (National Research Agency; ANR-11-LABX-0016-01) and (ii) of SIRIC ILIAD program (National Cancer Institute, Ministry of Health and the Institute for Health and Medical Research; INCa-DGOS-Inserm_12558). 
Author Manuscript Published OnlineFirst on January 10, 2020; DOI: 10.1158/2326-6066.CIR-18-0749

Author manuscripts have been peer reviewed and accepted for publication but have not yet been edited.

\section{References}

1. Okabe Y, Medzhitov R. Tissue biology perspective on macrophages. Nat Immunol. 2016;17:9-17.

2. Sica A, Mantovani A. Macrophage plasticity and polarization: in vivo veritas. J Clin Invest. 2012;122:787-95.

3. Xue J, Schmidt SV, Sander J, Draffehn A, Krebs W, Quester I, et al. Transcriptomebased network analysis reveals a spectrum model of human macrophage activation. Immunity. 2014;40:274-88.

4. Mosser DM, Edwards JP. Exploring the full spectrum of macrophage activation. Nat Rev Immunol. 2008;8:958-69.

5. Mantovani A, Sozzani S, Locati M, Allavena P, Sica A. Macrophage polarization: tumor-associated macrophages as a paradigm for polarized M2 mononuclear phagocytes. Trends Immunol. 2002;23:549-55.

6. Mantovani A, Marchesi F, Malesci A, Laghi L, Allavena P. Tumour-associated macrophages as treatment targets in oncology. Nat Rev Clin Oncol. 2017;14:399-416.

7. Mitsi E, Kamng’ona R, Rylance J, Solórzano C, Jesus Reiné J, Mwandumba HC, et al. Human alveolar macrophages predominately express combined classical M1 and M2 surface markers in steady state. Respir Res. 2018;19:66.

8. Moganti K, Li F, Schmuttermaier C, Riemann S, Klüter H, Gratchev A, et al. Hyperglycemia induces mixed M1/M2 cytokine profile in primary human monocytederived macrophages. Immunobiology. 2017;222:952-9.

9. Biswas SK, Gangi L, Paul S, Schioppa T, Saccani A, Sironi M, et al. A distinct and unique transcriptional program expressed by tumor-associated macrophages (defective NF-kappaB and enhanced IRF-3/STAT1 activation). Blood. 2006;107:2112-22.

10. Reinartz S, Schumann T, Finkernagel F, Wortmann A, Jansen JM, Meissner W, et al. Mixed-polarization phenotype of ascites-associated macrophages in human ovarian carcinoma: correlation of CD163 expression, cytokine levels and early relapse. Int J Cancer. 2014;134:32-42.

11. Müller S, Kohanbash G, Liu SJ, Alvarado B, Carrera D, Bhaduri A, et al. Single-cell profiling of human gliomas reveals macrophage ontogeny as a basis for regional differences in macrophage activation in the tumor microenvironment. Genome Biol. 2017; 18:234.

12. Azizi E, Carr AJ, Plitas G, Cornish AE, Konopacki C, Prabhakaran S, et al. Single-Cell Map of Diverse Immune Phenotypes in the Breast Tumor Microenvironment. Cell. 2018;174:1293-1308.e36.

13. Chevrier S, Levine JH, Zanotelli VRT, Silina K, Schulz D, Bacac M, et al. An Immune Atlas of Clear Cell Renal Cell Carcinoma. Cell. 2017;169:736-749.e18. 
Author Manuscript Published OnlineFirst on January 10, 2020; DOI: 10.1158/2326-6066.CIR-18-0749

Author manuscripts have been peer reviewed and accepted for publication but have not yet been edited.

14. Raes G, Van den Bergh R, De Baetselier P, Ghassabeh GH, Scotton C, Locati M, et al. Arginase-1 and Ym1 are markers for murine, but not human, alternatively activated myeloid cells. J Immunol. 2005;174:6561; author reply 6561-6562.

15. Jeannin P, Paolini L, Adam C, Delneste Y. The roles of CSFs on the functional polarization of tumor-associated macrophages. FEBS J. 2018;285:680-99.

16. Mantovani A, Sica A, Sozzani S, Allavena P, Vecchi A, Locati M. The chemokine system in diverse forms of macrophage activation and polarization. Trends Immunol. 2004;25:677-86.

17. Gentles AJ, Newman AM, Liu CL, Bratman SV, Feng W, Kim D, et al. The prognostic landscape of genes and infiltrating immune cells across human cancers. Nat Med. 2015;21:938-45.

18. Song L, Asgharzadeh S, Salo J, Engell K, Wu H, Sposto R, et al. Valpha24-invariant NKT cells mediate antitumor activity via killing of tumor-associated macrophages. $\mathbf{J}$ Clin Invest. 2009;119:1524-36.

19. Smith MP, Sanchez-Laorden B, O’Brien K, Brunton H, Ferguson J, Young H, et al. The immune microenvironment confers resistance to MAPK pathway inhibitors through macrophage-derived TNF $\alpha$. Cancer Discov. 2014;4:1214-29.

20. Vander Heiden MG, Cantley LC, Thompson CB. Understanding the Warburg effect: the metabolic requirements of cell proliferation. Science. 2009;324:1029-33.

21. Sun S, Li H, Chen J, Qian Q. Lactic Acid: No Longer an Inert and End-Product of Glycolysis. Physiology (Bethesda). 2017;32:453-63.

22. Hirschhaeuser F, Sattler UGA, Mueller-Klieser W. Lactate: a metabolic key player in cancer. Cancer Res. 2011;71:6921-5.

23. $\mathrm{Hu} \mathrm{X}, \mathrm{Chao} \mathrm{M}, \mathrm{Wu} \mathrm{H}$. Central role of lactate and proton in cancer cell resistance to glucose deprivation and its clinical translation. Signal Transduct Target Ther. 2017;2:16047.

24. Gottfried E, Kunz-Schughart LA, Ebner S, Mueller-Klieser W, Hoves S, Andreesen R, et al. Tumor-derived lactic acid modulates dendritic cell activation and antigen expression. Blood. 2006;107:2013-21.

25. Fischer K, Hoffmann P, Voelkl S, Meidenbauer N, Ammer J, Edinger M, et al. Inhibitory effect of tumor cell-derived lactic acid on human T cells. Blood. 2007;109:3812-9.

26. Angelin A, Gil-de-Gómez L, Dahiya S, Jiao J, Guo L, Levine MH, et al. Foxp3 Reprograms T Cell Metabolism to Function in Low-Glucose, High-Lactate Environments. Cell Metab. 2017;25:1282-1293.e7.

27. Romero-Garcia S, Moreno-Altamirano MMB, Prado-Garcia H, Sánchez-García FJ. Lactate Contribution to the Tumor Microenvironment: Mechanisms, Effects on Immune Cells and Therapeutic Relevance. Front Immunol. 2016;7:52. 
Author Manuscript Published OnlineFirst on January 10, 2020; DOI: 10.1158/2326-6066.CIR-18-0749

Author manuscripts have been peer reviewed and accepted for publication but have not yet been edited.

28. Colegio OR, Chu N-Q, Szabo AL, Chu T, Rhebergen AM, Jairam V, et al. Functional polarization of tumour-associated macrophages by tumour-derived lactic acid. Nature. 2014;513:559-63.

29. Carmona-Fontaine C, Deforet M, Akkari L, Thompson CB, Joyce JA, Xavier JB. Metabolic origins of spatial organization in the tumor microenvironment. Proc Natl Acad Sci USA. 2017;114:2934-9.

30. Laoui D, Van Overmeire E, Di Conza G, Aldeni C, Keirsse J, Morias Y, et al. Tumor hypoxia does not drive differentiation of tumor-associated macrophages but rather finetunes the M2-like macrophage population. Cancer Res. 2014;74:24-30.

31. Hobson-Gutierrez SA, Carmona-Fontaine C. The metabolic axis of macrophage and immune cell polarization. Dis Model Mech. 2018;11.

32. Preisser L, Miot C, Le Guillou-Guillemette H, Beaumont E, Foucher ED, Garo E, et al. IL-34 and macrophage colony-stimulating factor are overexpressed in hepatitis $\mathrm{C}$ virus fibrosis and induce profibrotic macrophages that promote collagen synthesis by hepatic stellate cells. Hepatology. 2014;60:1879-90.

33. Vandesompele J, De Preter K, Pattyn F, Poppe B, Van Roy N, De Paepe A, et al. Accurate normalization of real-time quantitative RT-PCR data by geometric averaging of multiple internal control genes. Genome Biol. 2002;3:RESEARCH0034.

34. Brand A, Singer K, Koehl GE, Kolitzus M, Schoenhammer G, Thiel A, et al. LDHAAssociated Lactic Acid Production Blunts Tumor Immunosurveillance by T and NK Cells. Cell Metab. 2016;24:657-71.

35. Duluc D, Delneste Y, Tan F, Moles M-P, Grimaud L, Lenoir J, et al. Tumor-associated leukemia inhibitory factor and IL-6 skew monocyte differentiation into tumor-associated macrophage-like cells. Blood. 2007;110:4319-30.

36. Polański R, Hodgkinson CL, Fusi A, Nonaka D, Priest L, Kelly P, et al. Activity of the monocarboxylate transporter 1 inhibitor AZD3965 in small cell lung cancer. Clin Cancer Res. 2014;20:926-37.

37. Izquierdo E, Cuevas VD, Fernández-Arroyo S, Riera-Borrull M, Orta-Zavalza E, Joven $\mathrm{J}$, et al. Reshaping of Human Macrophage Polarization through Modulation of Glucose Catabolic Pathways. J Immunol. 2015;195:2442-51.

38. Hernandez C, Huebener P, Schwabe RF. Damage-associated molecular patterns in cancer: a double-edged sword. Oncogene. 2016;35:5931-41.

39. Lacey DC, Achuthan A, Fleetwood AJ, Dinh H, Roiniotis J, Scholz GM, et al. Defining GM-CSF- and macrophage-CSF-dependent macrophage responses by in vitro models. J Immunol. 2012;188:5752-65.

40. Nagarsheth N, Wicha MS, Zou W. Chemokines in the cancer microenvironment and their relevance in cancer immunotherapy. Nat Rev Immunol. 2017;17:559-72. 
Author Manuscript Published OnlineFirst on January 10, 2020; DOI: 10.1158/2326-6066.CIR-18-0749

Author manuscripts have been peer reviewed and accepted for publication but have not yet been edited.

41. Martínez D, Vermeulen M, von Euw E, Sabatté J, Maggíni J, Ceballos A, et al. Extracellular acidosis triggers the maturation of human dendritic cells and the production of IL-12. J Immunol. 2007;179:1950-9.

42. Rajamäki K, Nordström T, Nurmi K, Åkerman KEO, Kovanen PT, Öörni K, et al. Extracellular acidosis is a novel danger signal alerting innate immunity via the NLRP3 inflammasome. J Biol Chem. 2013;288:13410-9.

43. Allavena P, Sica A, Garlanda C, Mantovani A. The Yin-Yang of tumor-associated macrophages in neoplastic progression and immune surveillance. Immunol Rev. 2008;222:155-61.

44. Martinez FO, Helming L, Milde R, Varin A, Melgert BN, Draijer C, et al. Genetic programs expressed in resting and IL-4 alternatively activated mouse and human macrophages: similarities and differences. Blood. 2013;121:e57-69.

45. Chomarat P, Banchereau J, Davoust J, Palucka AK. IL-6 switches the differentiation of monocytes from dendritic cells to macrophages. Nat Immunol. 2000;1:510-4.

46. Gliniak BC, Rohrschneider LR. Expression of the M-CSF receptor is controlled posttranscriptionally by the dominant actions of GM-CSF or multi-CSF. Cell. 1990;63:1073-83.

47. Brochériou I, Maouche S, Durand H, Braunersreuther V, Le Naour G, Gratchev A, et al. Antagonistic regulation of macrophage phenotype by M-CSF and GM-CSF: implication in atherosclerosis. Atherosclerosis. 2011;214:316-24.

48. Conway JG, McDonald B, Parham J, Keith B, Rusnak DW, Shaw E, et al. Inhibition of colony-stimulating-factor-1 signaling in vivo with the orally bioavailable cFMS kinase inhibitor GW2580. Proc Natl Acad Sci USA. 2005;102:16078-83.

49. Foucher ED, Blanchard S, Preisser L, Garo E, Ifrah N, Guardiola P, et al. IL-34 induces the differentiation of human monocytes into immunosuppressive macrophages. antagonistic effects of GM-CSF and IFN $\gamma$. PLoS ONE. 2013;8:e56045.

50. Lee DC, Sohn HA, Park Z-Y, Oh S, Kang YK, Lee K-M, et al. A lactate-induced response to hypoxia. Cell. 2015;161:595-609.

51. De Saedeleer CJ, Copetti T, Porporato PE, Verrax J, Feron O, Sonveaux P. Lactate activates HIF-1 in oxidative but not in Warburg-phenotype human tumor cells. PLoS ONE. 2012;7:e46571.

52. Lee K, Zhang H, Qian DZ, Rey S, Liu JO, Semenza GL. Acriflavine inhibits HIF-1 dimerization, tumor growth, and vascularization. Proc Natl Acad Sci USA. 2009; 106:17910-5.

53. Imtiyaz HZ, Williams EP, Hickey MM, Patel SA, Durham AC, Yuan L-J, et al. Hypoxia-inducible factor 2alpha regulates macrophage function in mouse models of acute and tumor inflammation. J Clin Invest. 2010;120:2699-714.

54. Lu H, Forbes RA, Verma A. Hypoxia-inducible factor 1 activation by aerobic glycolysis implicates the Warburg effect in carcinogenesis. J Biol Chem. 2002;277:23111-5. 
Author Manuscript Published OnlineFirst on January 10, 2020; DOI: 10.1158/2326-6066.CIR-18-0749

Author manuscripts have been peer reviewed and accepted for publication but have not yet been edited.

55. Warburg O, Wind F, Negelein E. THE METABOLISM OF TUMORS IN THE BODY. J Gen Physiol. 1927;8:519-30.

56. Sonveaux P, Copetti T, De Saedeleer CJ, Végran F, Verrax J, Kennedy KM, et al. Targeting the lactate transporter MCT1 in endothelial cells inhibits lactate-induced HIF1 activation and tumor angiogenesis. PLoS ONE. 2012;7:e33418.

57. Wenes M, Shang M, Di Matteo M, Goveia J, Martín-Pérez R, Serneels J, et al. Macrophage Metabolism Controls Tumor Blood Vessel Morphogenesis and Metastasis. Cell Metab. 2016;24:701-15.

58. Chambers SK. Role of CSF-1 in progression of epithelial ovarian cancer. Future Oncol. 2009;5:1429-40.

59. Ide H, Seligson DB, Memarzadeh S, Xin L, Horvath S, Dubey P, et al. Expression of colony-stimulating factor 1 receptor during prostate development and prostate cancer progression. Proc Natl Acad Sci USA. 2002;99:14404-9.

60. Kacinski BM, Scata KA, Carter D, Yee LD, Sapi E, King BL, et al. FMS (CSF-1 receptor) and CSF-1 transcripts and protein are expressed by human breast carcinomas in vivo and in vitro. Oncogene. 1991;6:941-52.

61. Hallett MA, Venmar KT, Fingleton B. Cytokine stimulation of epithelial cancer cells: the similar and divergent functions of IL-4 and IL-13. Cancer Res. 2012;72:6338-43.

62. Greten FR, Grivennikov SI. Inflammation and Cancer: Triggers, Mechanisms, and Consequences. Immunity. 2019;51:27-41.

63. Shalapour S, Karin M. Pas de Deux: Control of Anti-tumor Immunity by CancerAssociated Inflammation. Immunity. 2019;51:15-26.

64. Chen J, Yao Y, Gong C, Yu F, Su S, Chen J, et al. CCL18 from tumor-associated macrophages promotes breast cancer metastasis via PITPNM3. Cancer Cell. 2011;19:541-55.

65. Su S, Liao J, Liu J, Huang D, He C, Chen F, et al. Blocking the recruitment of naive CD4+ T cells reverses immunosuppression in breast cancer. Cell Res. 2017;27:461-82.

66. Delneste Y, Charbonnier P, Herbault N, Magistrelli G, Caron G, Bonnefoy J-Y, et al. Interferon-gamma switches monocyte differentiation from dendritic cells to macrophages. Blood. 2003;101:143-50.

67. Lou J, Low-Nam ST, Kerkvliet JG, Hoppe AD. Delivery of CSF-1R to the lumen of macropinosomes promotes its destruction in macrophages. J Cell Sci. 2014;127:522839.

68. Verreck FAW, de Boer T, Langenberg DML, Hoeve MA, Kramer M, Vaisberg E, et al. Human IL-23-producing type 1 macrophages promote but IL-10-producing type 2 macrophages subvert immunity to (myco)bacteria. Proc Natl Acad Sci USA. $2004 ; 101: 4560-5$. 
69. Garcia S, Hartkamp LM, Malvar-Fernandez B, van Es IE, Lin H, Wong J, et al. Colonystimulating factor (CSF) 1 receptor blockade reduces inflammation in human and murine models of rheumatoid arthritis. Arthritis Res Ther. 2016;18:75.

70. Hamilton JA, Cook AD, Tak PP. Anti-colony-stimulating factor therapies for inflammatory and autoimmune diseases. Nat Rev Drug Discov. 2016;16:53-70.

71. Peyssonnaux C, Cejudo-Martin P, Doedens A, Zinkernagel AS, Johnson RS, Nizet V. Cutting edge: Essential role of hypoxia inducible factor-1alpha in development of lipopolysaccharide-induced sepsis. J Immunol. 2007;178:7516-9.

72. Casazza A, Di Conza G, Wenes M, Finisguerra V, Deschoemaeker S, Mazzone M. Tumor stroma: a complexity dictated by the hypoxic tumor microenvironment. Oncogene. 2014;33:1743-54.

73. Yan W-L, Shen K-Y, Tien C-Y, Chen Y-A, Liu S-J. Recent progress in GM-CSF-based cancer immunotherapy. Immunotherapy. 2017;9:347-60.

74. Bayne LJ, Beatty GL, Jhala N, Clark CE, Rhim AD, Stanger BZ, et al. Tumor-derived granulocyte-macrophage colony-stimulating factor regulates myeloid inflammation and T cell immunity in pancreatic cancer. Cancer Cell. 2012;21:822-35.

75. Pylayeva-Gupta Y, Lee KE, Hajdu CH, Miller G, Bar-Sagi D. Oncogenic Kras-induced GM-CSF production promotes the development of pancreatic neoplasia. Cancer Cell. 2012;21:836-47.

76. Reggiani F, Labanca V, Mancuso P, Rabascio C, Talarico G, Orecchioni S, et al. Adipose Progenitor Cell Secretion of GM-CSF and MMP9 Promotes a Stromal and Immunological Microenvironment That Supports Breast Cancer Progression. Cancer Res. 2017;77:5169-82.

77. Bhattacharya P, Budnick I, Singh M, Thiruppathi M, Alharshawi K, Elshabrawy H, et al. Dual Role of GM-CSF as a Pro-Inflammatory and a Regulatory Cytokine: Implications for Immune Therapy. J Interferon Cytokine Res. 2015;35:585-99.

78. Achkova D, Maher J. Role of the colony-stimulating factor (CSF)/CSF-1 receptor axis in cancer. Biochem Soc Trans. 2016;44:333-41. 


\section{Figure legends}

\section{Figure 1. Lactate induces monocyte differentiation into CD14 ${ }^{\text {high }} \mathrm{CD163}^{\text {high }}$}

macrophages. A. Human monocytes were cultured with GM-CSF and the indicated concentrations of lactate. Results are expressed as a percentage of viable cells at day $5(n=5)$; shaded area, range of lactate concentrations in solid tumors (21). B and C. CD1a, CD14 and CD163 expression was assessed by flow cytometry at day 5 on GM-M $\Phi$, GM+LA-M $\Phi$, MMФ and Mo-DC. Results are expressed as RFI values $(n=5)(\mathbf{B})$ or representative of one of 5 experiments (C). D. Relative expression of CD14 and CD163 mRNA at day $5(\mathrm{n}=3)$. E. The expression of membrane CD163 was evaluated by flow cytometry at the indicated time points $(\mathrm{n}=5)$. A, C-E. mean \pm SEM; $* * \mathrm{p}<0.01$, *** $\mathrm{p}<0.001$ (Wilcoxon test or 2-way ANOVA).

\section{Figure 2. The effects of lactate are dependent on its internalization and metabolization.}

A. Human monocytes were generated under acidosis, lactosis or lactic acidosis, without or with CHC or AZD3965 (AZD). The expression of CD163 and CD14 was assessed by flow cytometry at day 5 (left panels) and IL1 $\beta$ and IL12p70 were quantified after 24 h stimulation with LPS (right panels) (n=5). B. Monocytes were cultured with GM-CSF and $10 \mathrm{mM}{ }^{13} \mathrm{C}$ lactate sodium $(\mathrm{pH}=6.5)$; samples were analyzed at day 5 by NMR (left panel, $\mathrm{n}=3$ ) and LCMS (right panel, $\mathrm{n}=4$ ). LC-MS, results are expressed as a percentage of ${ }^{13} \mathrm{C}$ isotopic enrichment. A-B. mean \pm SEM; $* \mathrm{p}<0.05$, ** $\mathrm{p}<0.01$, *** $\mathrm{p}<0.001$ (Wilcoxon test).

Figure 3. Lactate confers an inflammatory phenotype to human macrophages. A. Day-5 macrophages were stimulated with LPS for $24 \mathrm{~h}$ before quantification of IL1 $\beta$, IL6, TNF $\alpha$, CXCL8, IL10, IL12p70 and CXCL10 (n=7). B. Day-5 GM-MФ (blue) and GM+LA-MФ (red) were stimulated for $24 \mathrm{~h}$ with LPS before intracellular staining with anti-TNF $\alpha$ and antiIL6. Dot plots, gating strategy; histograms, levels of TNF $\alpha$ and IL6 (grey histograms, isotype control mAbs). Results are representative of one of 5 experiments. C. Relative expression of IL1 $\beta$, TNF $\alpha$, IL6 (upper panels), CXCL8, CCL2, CCL13, CXCL5, CXCL2, CXCL3, CXCL1, CCL18 and CCL24 (lower panels) mRNA by day-5 macrophages either unstimulated (left panel) or stimulated for $6 \mathrm{~h}$ with LPS (right panel) ( $\mathrm{n}=3$ ). A, C. mean $\pm \mathrm{SEM} ;{ }^{*} \mathrm{p}<0.05$, ** $\mathrm{p}<0.01, * * * \mathrm{p}<0.001$ (Wilcoxon test). 
Figure 4. Lactate induces the generation of macrophages with trophic properties. A. Relative HB-EGF, TGF $\alpha$, EREG, HGF, IL20, OSM, VEGF-A and PDGF-BB mRNA expression at day $5(\mathrm{n}=3) .{ }^{\varnothing}, 6 \mathrm{~h}$ stimulation with LPS. B. Day-5 macrophages were stimulated for $24 \mathrm{~h}$ with LPS before quantification of HB-EGF, TGF $\alpha$, IL20, OSM, VEGF-A, and ET-1 (n=6). nd, not done. A and B. mean \pm SEM; $* \mathrm{p}<0.05$, ** $\mathrm{p}<0.01$, *** $\mathrm{p}<0.001$ (Wilcoxon test).

Figure 5. The expression of selected markers by GM+LA-MФ is dependent of autocrine M-CSF consumption. A. Relative mRNA expression in day-5 GM-M $\Phi, \mathrm{GM}+\mathrm{LA}-\mathrm{M} \Phi$ and M-MФ (3 different donors) was determined by qPCR. Specific gene expression was calculated using the $2^{-\triangle \Delta \mathrm{CT}}$ method using RPS18, EF1A, TBP, RPL13A and PPIA as references. The normalized values for each gene are depicted according to a color scale, where red and blue represent expression above and below the mean, respectively. B. GM-MФ and GM+LA-M $\Phi$ were generated without or with GW2580 and the relative expression of SERPINB2, FOLR2, SEPP1 and CD163 mRNA expression was determined at day $5(\mathrm{n}=5)$. C. M-CSF quantification in the supernatants collected at indicated time point $(n=5)$. D. CD115 expression (left panel) and sCD115 production (right panel) were determined at the indicated time points $(\mathrm{n}=3)$. E and F. GM-M $\Phi$ and $\mathrm{GM}+\mathrm{LA}-\mathrm{M} \Phi$ were generated without or with a neutralizing anti-M-CSF, a control mAb or GW2580. E. At day 5, the expression of CD163 and CD14 was determined $(n=4)$. F. Day-5 cells were stimulated for $24 \mathrm{~h}$ with LPS and VEGF-A, TGF $\alpha$, IL1 $\beta$ and TNF $\alpha$ were quantified in the supernatants $(n=5)$. B-E. mean \pm SEM; $* \mathrm{p}<0.05, * * \mathrm{p}<0.01, * * * \mathrm{p}<0.001$ (Wilcoxon test).

Figure 6. HIF-1 stabilization and lactate metabolization in GM+LA-MФ. A. The relative expression of M-CSF and CD115 mRNA was determined in monocytes cultured for $18 \mathrm{~h}$ with GM-CSF or GM-CSF plus lactate, without or with acriflavine (n=5). B-D. GM-M $\Phi$ and GM+LA-MФ were generated without or with acriflavine. The expression of CD163 and CD14 (B) and the relative expression of CD163, SEPP1, FOLR2 and SERPINB2 mRNA (C) were determined at day $5(\mathrm{n}=5)$. D. Day-5 macrophages were stimulated for $24 \mathrm{~h}$ with LPS and IL1 $\beta$, TNF $\alpha$, HB-EGF and OSM were quantified in cell culture supernatants $(\mathrm{n}=5)$. $\mathbf{E}$. GM+LA-MФ were generated without or with GSK2837808A and oxamic acid. The 
expression of CD14 and CD163 was determined at day 5 (left panels) and the production of IL1 $\beta$ and HBEGF was evaluated after a $24 \mathrm{~h}$ stimulation with LPS (right panels) $(n=5)$.

Figure 7. Ovarian tumor cell-derived lactate induces the generation of macrophages expressing inflammatory and pro-tumor mediators. Monocytes were co-cultured for 5 days with GM-CSF (GM-M $\Phi)$, in the absence or presence of the primary ovarian tumor cell CASC170, with or without CHC. A. The expression of CD163 (left panel) and CD14 (middle panel) was evaluated at day 5. Day-5 macrophages were stimulated for $24 \mathrm{~h}$ with LPS before quantification of IL1 $\beta$ (right panel) $(n=4)$. B. The relative expression of SEPP1, FOLR2, SATB1, EREG and OSM mRNA was assessed after $6 \mathrm{~h}$ stimulation with LPS $(\mathrm{n}=4)$. C. LPSstimulated or unstimulated cells suspension (after tumor dissociation) before intracellular staining with anti-CXCL8 and anti-IL1 $\beta$. Dot plots represent the gating strategy and histograms the intracellular expression of CXCL8 and IL1 $\beta$. Grey histograms, isotype control mAbs. Results are representative of one of 3 experiments. D. Relative expression of VEGF in CXCL8 $^{-}$IL1 $^{-}{ }^{-}$CXCL8 $^{+}$IL1 $^{-}{ }^{-}$and CXCL8 ${ }^{+}{\text {IL } 1 \beta^{+}}^{\text {TAM }}$ from 4 patients. A-D. mean \pm SEM; $* \mathrm{p}<0.05, * * \mathrm{p}<0.01, * * * \mathrm{p}<0.001$ (Wilcoxon test). 


\section{Figure 1}
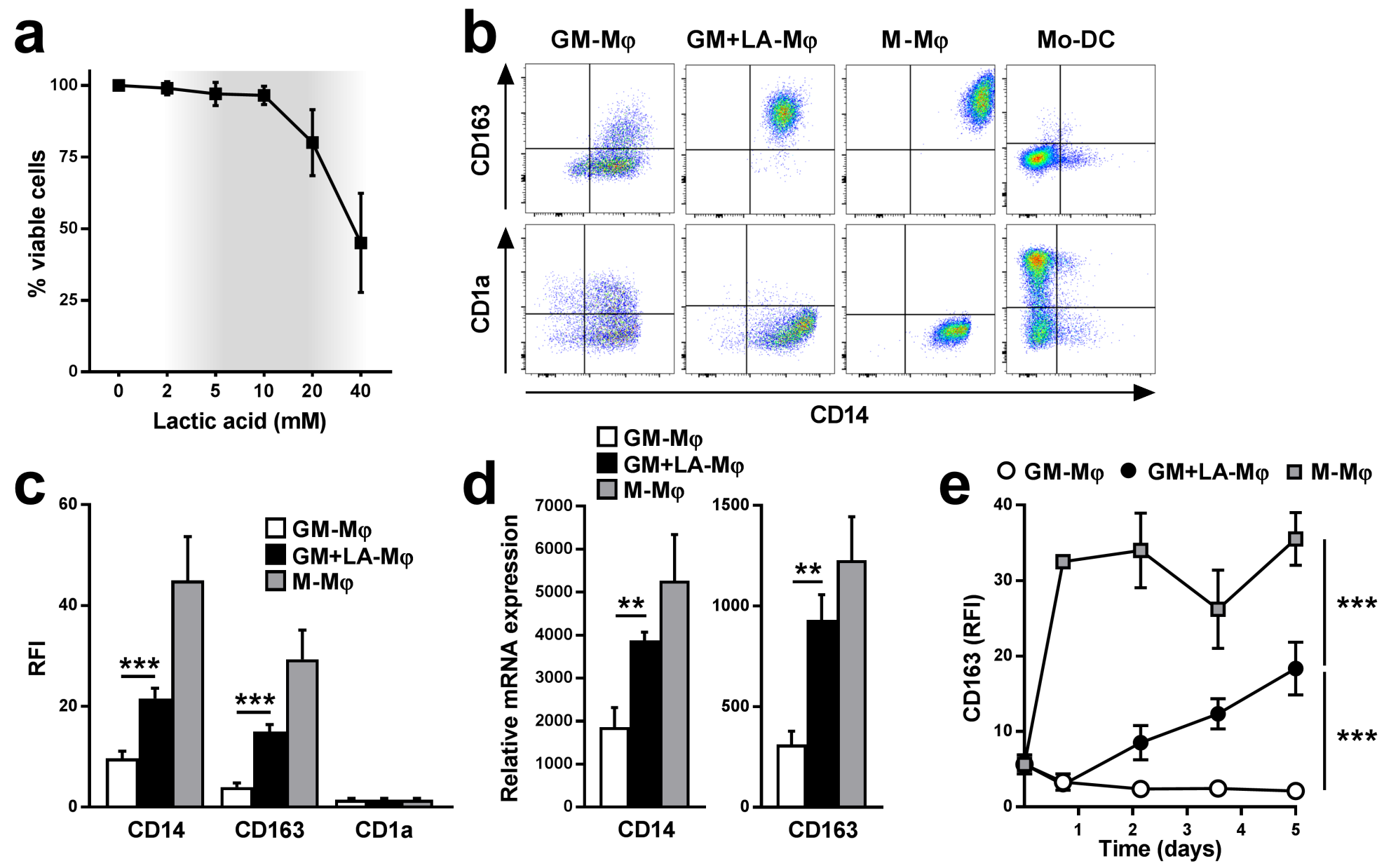
Figure 2
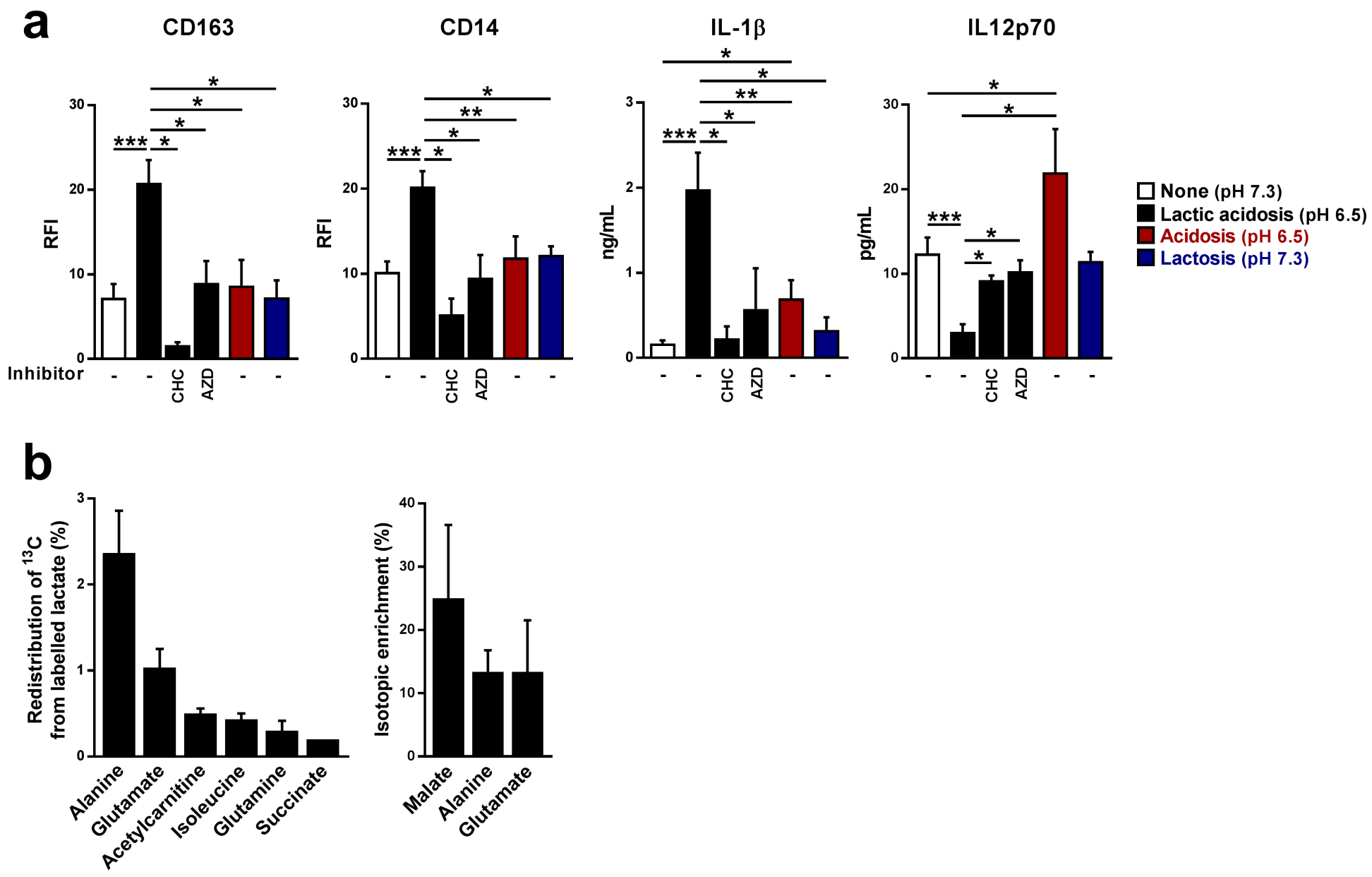


\section{Figure 3}

a $\square G M-M \varphi \square M+L A-M \varphi \square M-M \varphi$
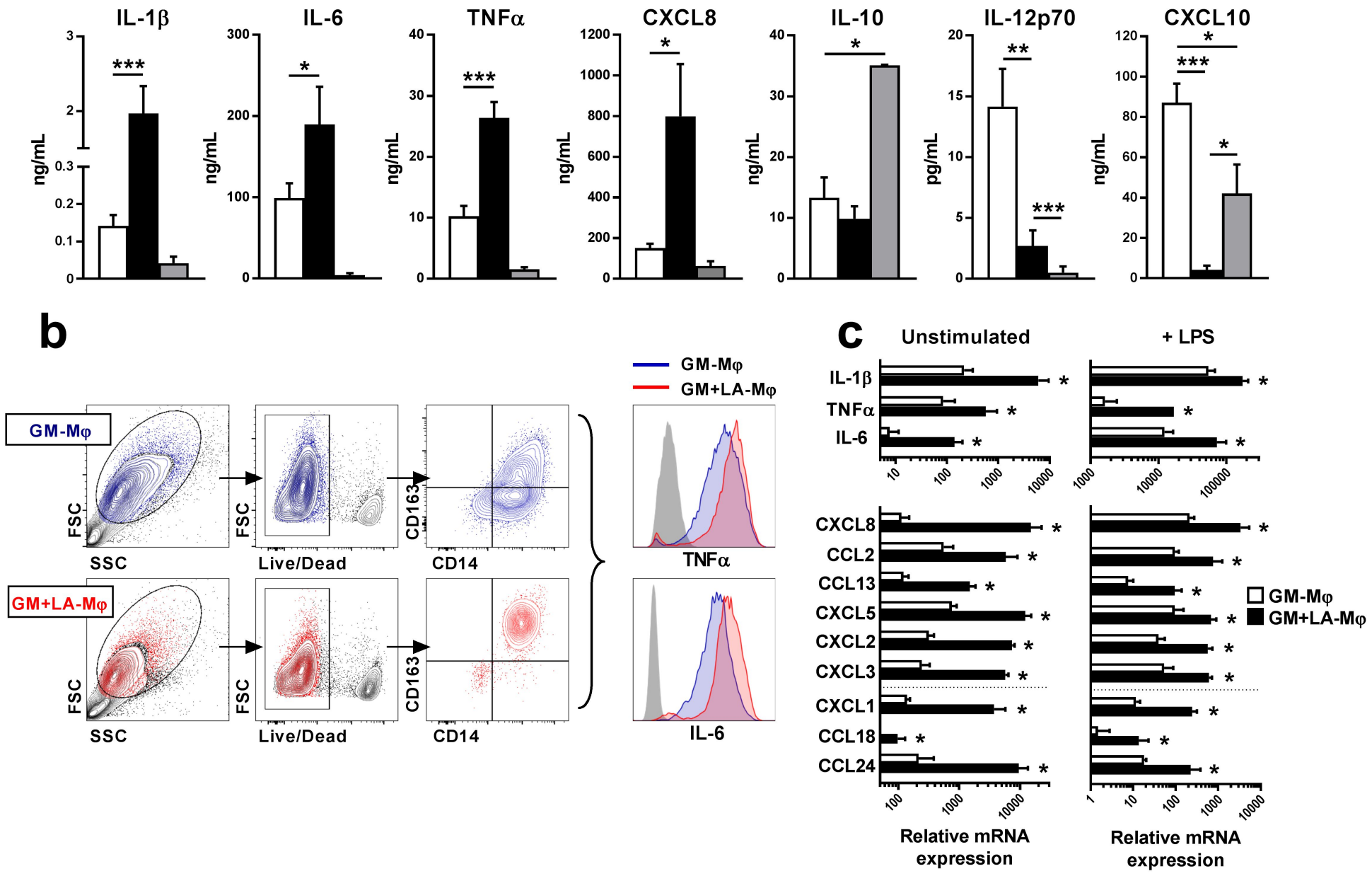
Figure 4
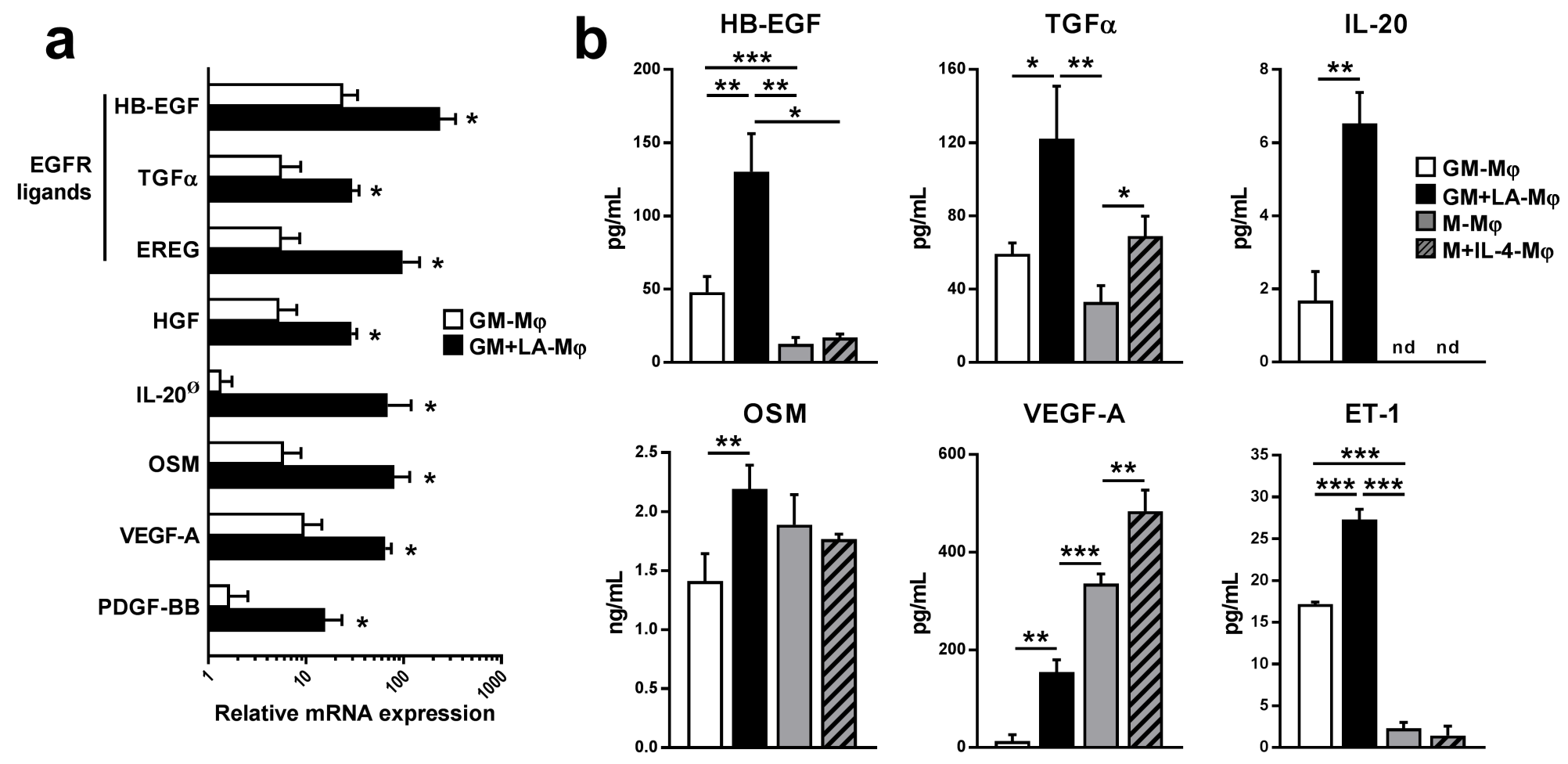


\section{Figure 5}

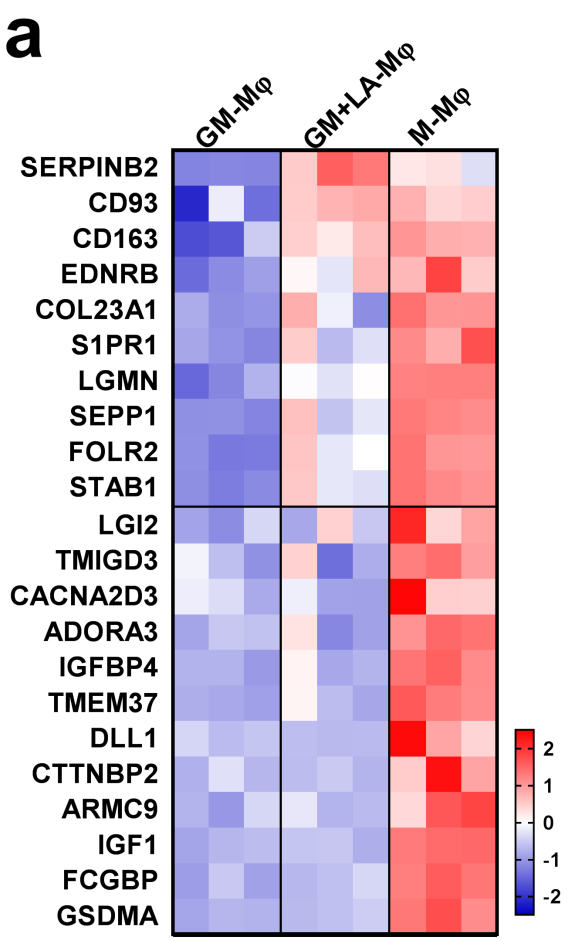

b $\begin{array}{cccc}\square G M-M \varphi & G M+L A-M \varphi & \square G M+L A-M \varphi+G W 2580 \\ \text { SERPINB2 } & \text { FOLR2 } & \text { SEPP1 } & \text { CD163 }\end{array}$

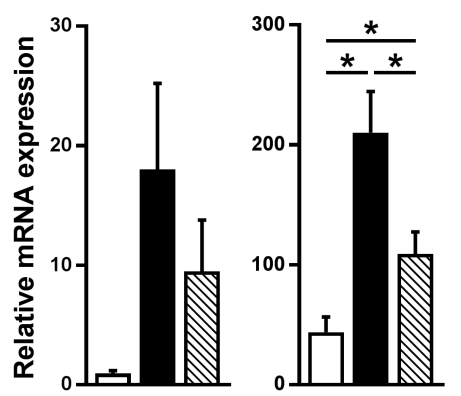

e

$$
\text { CD163 }
$$

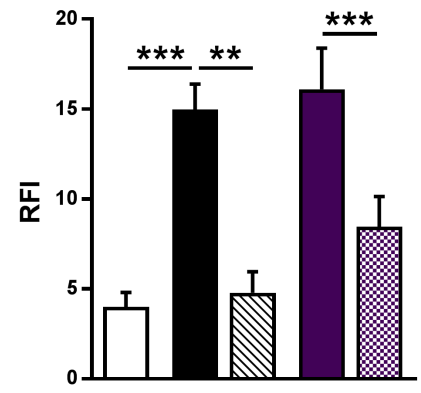

+ Control $A b$

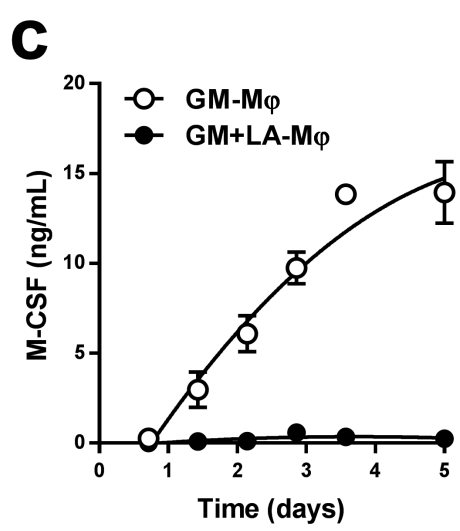

CD14

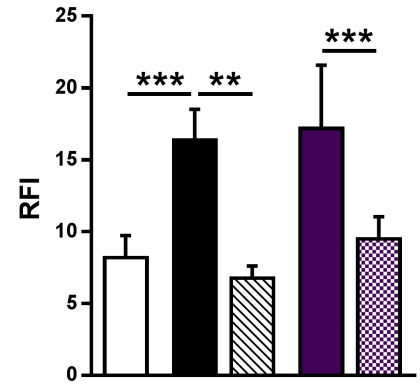

$\square$ GM-M

GM+LA-M $\varphi$

$\mathbb{Q}^{\mathrm{GM}+\mathrm{LA}-\mathrm{M} \varphi}$

+ GW2580

$\square^{\mathrm{GM}+\mathrm{LA}-\mathrm{M} \varphi}$

Q $\mathrm{GM}+\mathrm{LA}-\mathrm{M} \varphi$
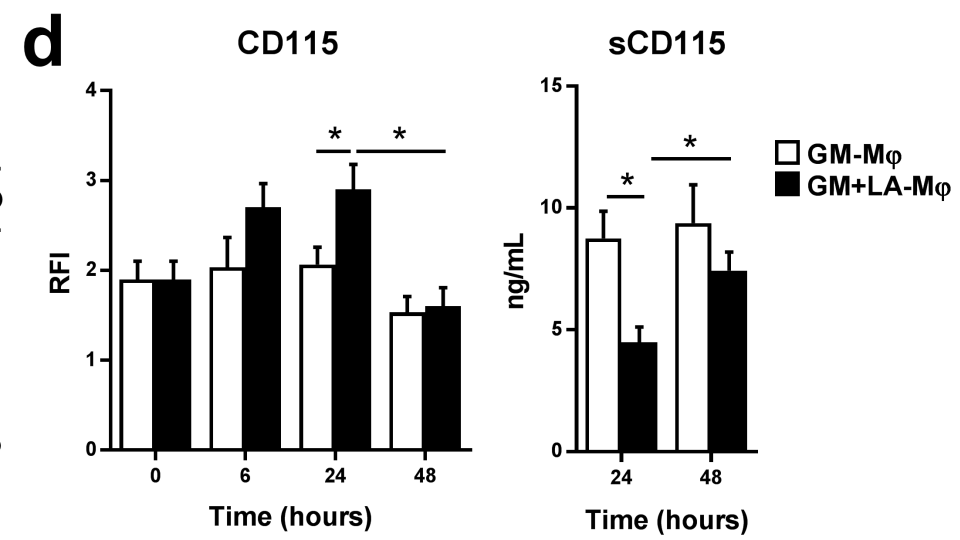

f $\square G M-M \varphi \quad G M+L A-M \varphi \quad \square G M+L A-M \varphi+G W 2580$ VEGF-A TGF $\alpha$

IL-1 $\beta$

TNF $\alpha$
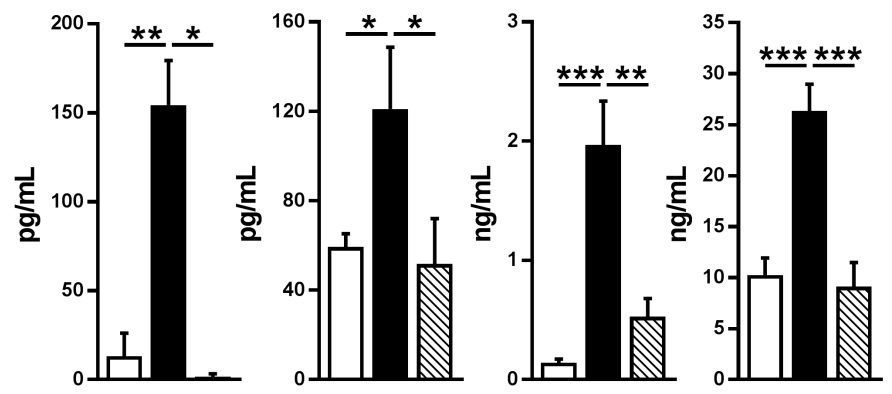


\section{Figure 6}
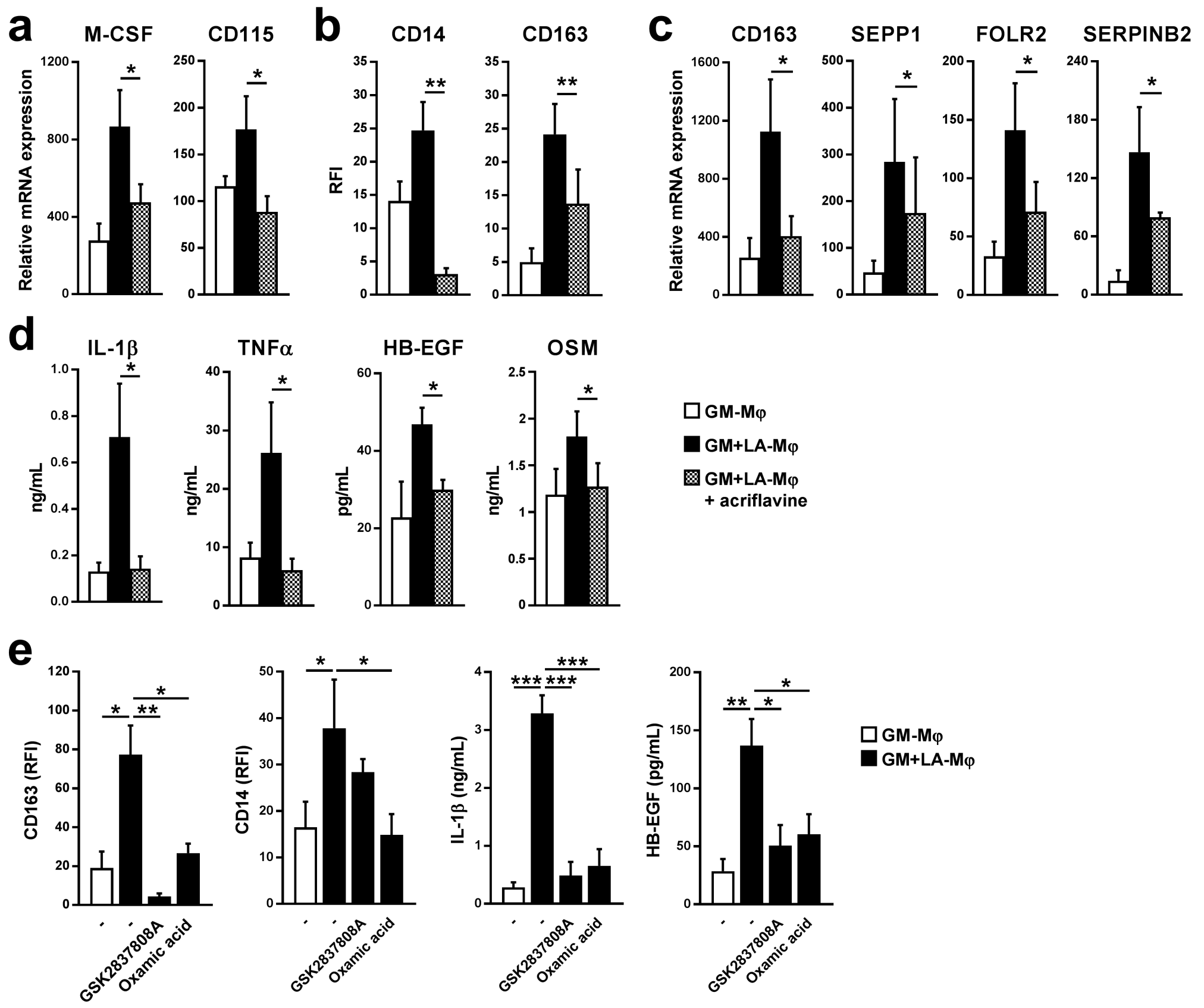


\section{Figure 7}

a
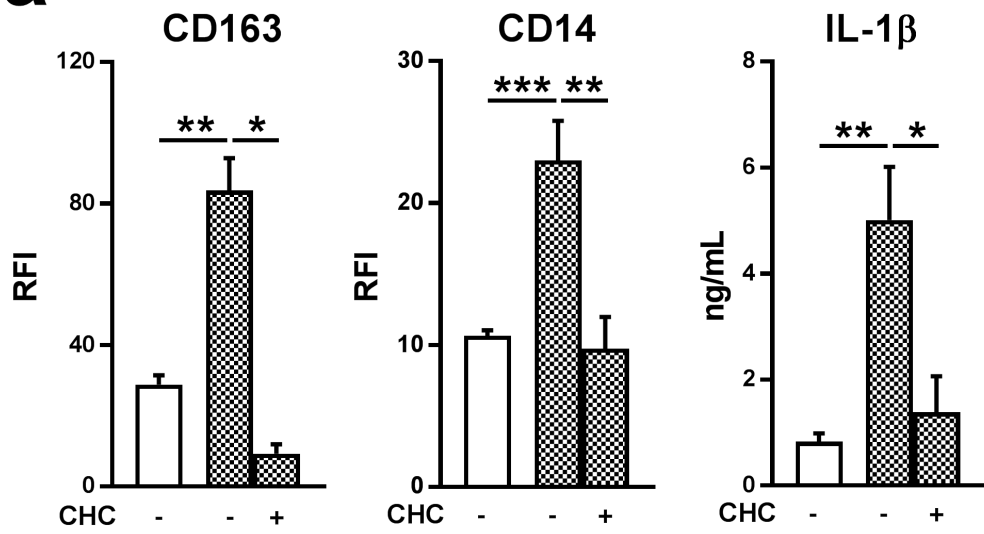

$\square \mathrm{GM}-\mathrm{M} \varphi$

$\otimes \mathrm{GM}-\mathrm{M} \varphi$ cocultured with CASC170 cells

b

SEPP1

FOLR2

STAB1

EREG

OSM
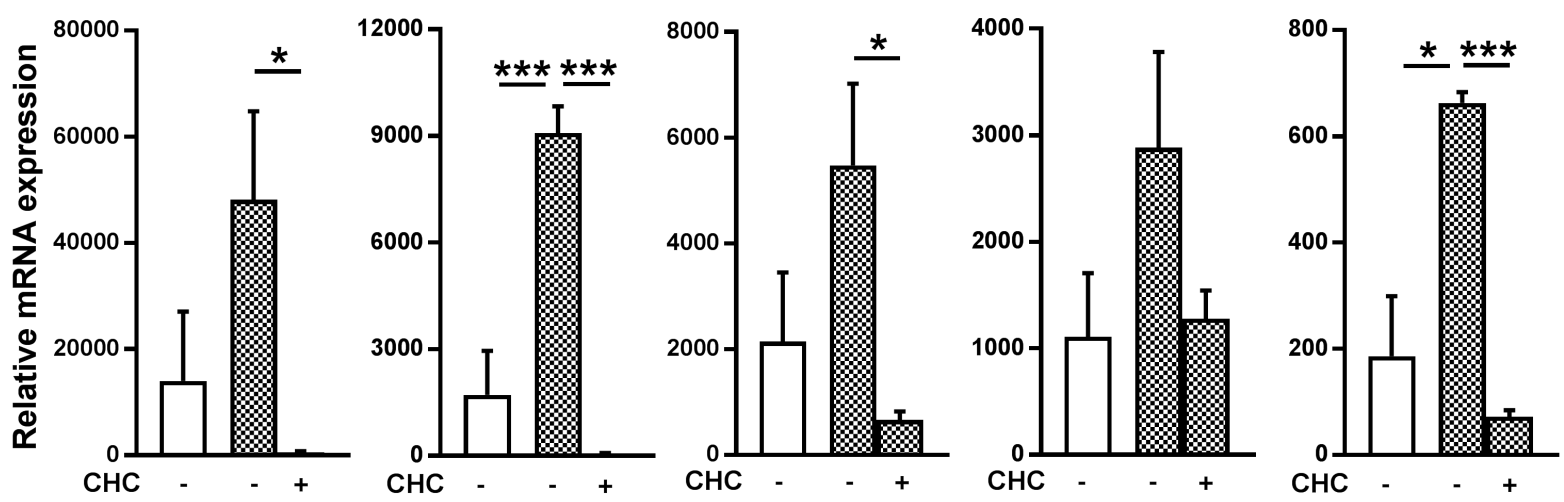

$\square \mathrm{GM}-\mathrm{M} \varphi$

冈 GM-M $\varphi$ cocultured with CASC170 cells
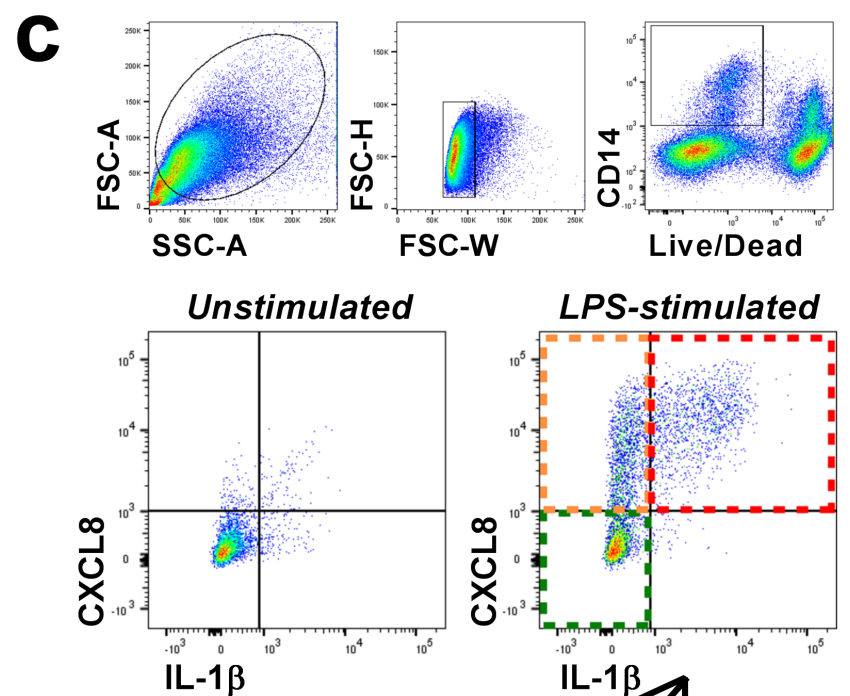

d
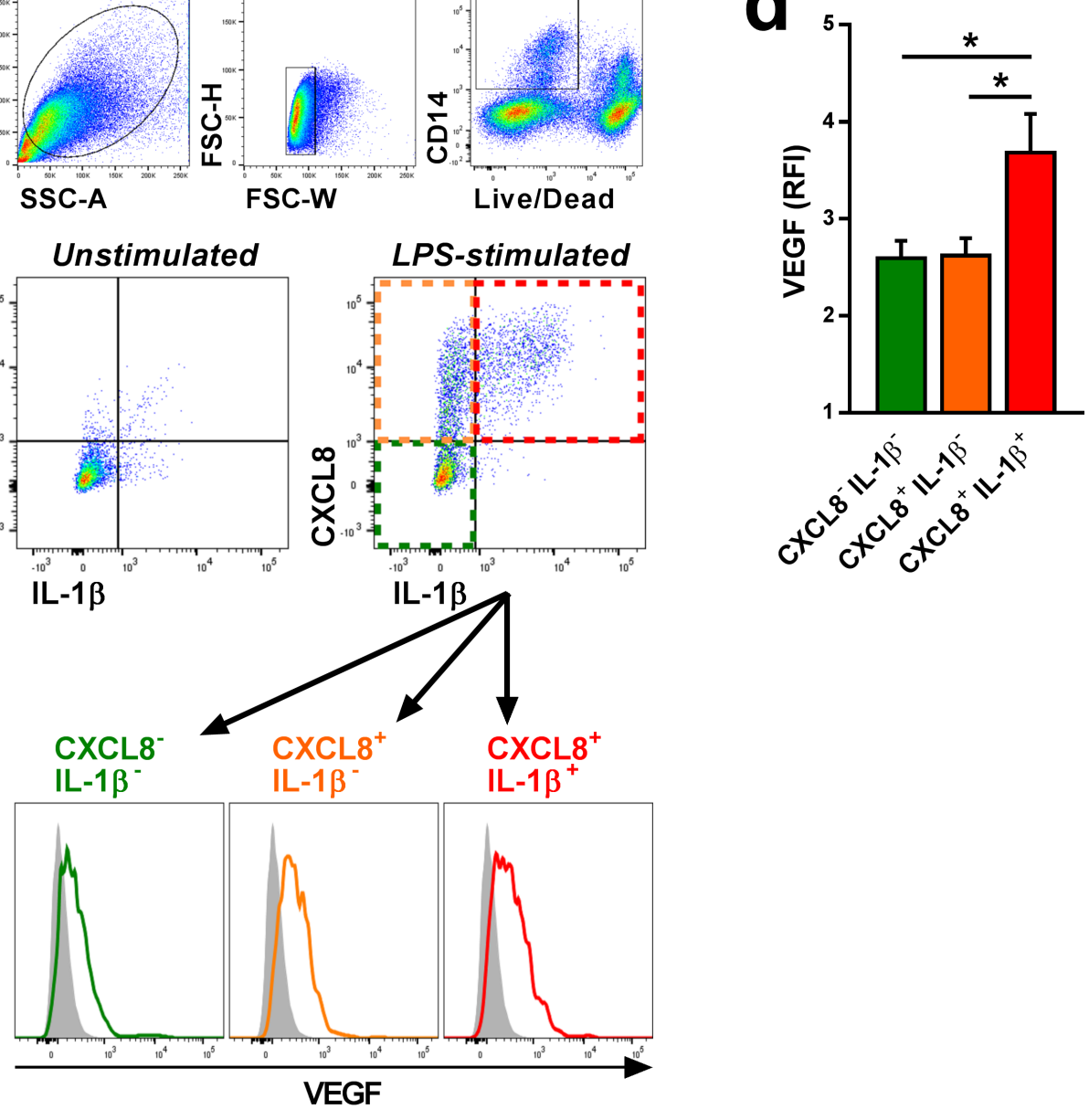


\title{
Cancer Immunology Research
}

\section{Lactic acidosis together with GM-CSF and M-CSF induces human macrophages toward an inflammatory pro-tumor phenotype}

Léa Paolini, Clément Adam, Céline Beauvillain, et al.

Cancer Immunol Res Published OnlineFirst January 10, 2020.

\author{
Updated version Access the most recent version of this article at: \\ doi:10.1158/2326-6066.CIR-18-0749 \\ Supplementary Access the most recent supplemental material at: \\ Material http://cancerimmunolres.aacrjournals.org/content/suppl/2020/01/10/2326-6066.CIR-18-0749.D \\ C1
}

Author Author manuscripts have been peer reviewed and accepted for publication but have not yet Manuscript been edited. 